\title{
The benefits of co-location in primary care practices: the perspectives of general practitioners and patients in 34 countries
}

\author{
M. Bonciani ${ }^{*}$ (D, W. Schäfer ${ }^{2}$, S. Barsanti ${ }^{1}$, S. Heinemann ${ }^{3,4}$ and P. P. Groenewegen ${ }^{2,5}$
}

\begin{abstract}
Background: There is no clear evidence as to whether the co-location of primary care professionals in the same facility positively influences their way of working and the quality of healthcare as perceived by patients. The aim of this study was to identify the relationships between general practitioner (GP) co-location with other GPs and/or other professionals and the GP outcomes and patients' experiences.

Methods: We wanted to test whether GP co-location is related to a broader range of services provided, the use of clinical governance tools and inter-professional collaboration, and whether the patients of co-located GPs perceive a better quality of care in terms of accessibility, comprehensiveness and continuity of care with their GPs. The source of data was the QUALICOPC study (Quality and Costs of Primary Care in Europe), which involved surveys of GPs and their patients in 34 countries, mostly in Europe. In order to study the relationships between GP co-location and both GPs' outcomes and patients' experience, multilevel linear regression analysis was carried out.
\end{abstract}

Results: The GP questionnaire was filled in by 7183 GPs and the patient experience questionnaire by 61,931 patients. Being co-located with at least one other professional is the most common situation of the GPs involved in the study. Compared with single-handed GP practices, GP co-location are positively associated with the GP outcomes. Considering the patients' perspective, comprehensiveness of care has the strongest negative relationship of GP co-location of all the dimensions of patient experiences analysed.

Conclusions: The paper highlights that GP mono- and multi-disciplinary co-location is related to positive outcomes at a GP level, such as a broader provision of technical procedures, increased collaboration among different providers and wider coordination with secondary care. However, GP co-location, particularly in a multidisciplinary setting, is related to less positive patient experiences, especially in countries with health systems characterised by a weak primary care structure.

\section{Background}

The co-location of professionals in primary care settings involves a structural change in healthcare provision in many countries where traditionally general practitioners (GPs) work in single-handed practices, and in these contexts co-location is adopted to improve primary care, in pilot areas or more widely $[1,5,7]$. The co-location of GPs with other professionals may positively change their way of working

\footnotetext{
* Correspondence: m.bonciani@santannapisa.it

${ }^{1}$ Laboratorio Management e Sanità, Institute of Management, Scuola

Superiore Sant'Anna, Pisa, Italy

Full list of author information is available at the end of the article
}

and may also improve the quality of healthcare as perceived by patients. In this article, we analyse how GP co-location relates to the experiences of GPs and patients.

Co-location involves the logistic integration of professionals working together in the same facility. In our study, it has been defined through two dimensions: i) mono-professional co-location of GPs (usually with secretarial support); ii) multi-disciplinary co-location. Most of the current literature focuses on multi-disciplinary co-location.

In the West, there is considerable variation in the composition of primary care teams, with large 
differences in the mix of professions working with GPs within the same practice [22]. This may be related to the level of attention national policies give to co-locating GPs with other professionals as a strategy to improve integration in primary care. In fact, the co-location of GPs and other professionals in the same practice, as a single point of healthcare access, is often proposed as a change in the organisation of primary care delivery that may facilitate access to services. This co-location may also minimize fragmentation among the various providers involved in the patient care pathway, by reducing duplication and ensuring more responsiveness to users [9, 24, 40]. This is particularly important for patients with chronic conditions or multi-morbidity [6, 55], who require a comprehensive approach and the involvement of different professionals in the provision of integrated care [20, 54]. The co-location of services and professionals in primary care can facilitate integration in the delivery of healthcare, prevention and rehabilitation services [48].

Professionals who are co-located in the same facility have more opportunities to meet and share information. Such increased interaction in colocated settings can enhance a mutual influence in decision-making and clinical practice [13]. This mutual influence and the need for coordination following the increased interactions are potentially important in terms of clinical governance. For instance, guidelines are more readily accepted as a result of local consensus discussions and contact with colleagues [23].

However, it has also been argued that professionals may consider that a mutual influence related to teamwork could negatively impact on their autonomy [8]. Consequently, GPs may oppose organisational changes that potentially promote teamwork, such as co-location in the same facility.

Co-location provides opportunities for collaboration but does not necessarily lead to it. There is mixed evidence on the role of co-location as a key driver for integration among professionals [39]. Many studies have shown that co-location facilitates multi-professional teamwork $[11,57]$ and the possibility to share information on patients and jointly define their care pathways $[4,12]$. However, colocation by itself has been shown to not necessarily lead to collaboration among professionals when they continue to work as separate providers [27, 36].

How the co-location of primary care professionals relates to patients' experiences is not yet clear. The underlying assumption is that a greater degree of organisational integration resulting from co-location benefits patients. Some studies have reported that the key aspect characterising co-location is joint working, which promotes better results for patients and an improvement in service quality, in terms of improved access to health services for patients and the increased satisfaction of patients [19]. However, other studies have highlighted that patients prefer single-handed or small practices [3], and that smaller practices are perceived as being more accessible [10].

Considering the controversial evidence, this study aims to analyse the relationship between GP colocation with other GPs and/or other professionals and the GPs' outcomes and patients' experiences. We expect that when GPs are co-located with other GPs and/or other professionals, they provide a broader range of services, use more clinical governance tools and collaborate more with other primary and secondary care professionals (GPs' outcomes). We also hypothesise that the patients of co-located GPs with other GPs and other professionals perceive a better quality of care in terms of accessibility, comprehensiveness of care and continuity of care with their GPs (patients' experiences). We expect that patients of GPs who are co-located with other GPs and/or other professionals, perceive a better quality of care by receiving more accessible care, with a more comprehensive approach which enables them to have answers to a broader range of common health problems and more continuity of information between primary and secondary care professionals, compared to patients of GPs in singlehanded practices.

Figure 1 summarizes the conceptual framework of this study. It shows how the structural and organisational dimension of healthcare, represented by GP co-location, can be related to different potential outcomes from the perspective of GPs and experiences from the perspective of patients. The two perspectives can sometimes be conflicted [38], however we hypothesise that both providers (GPs) and users (patients) converge in experiencing advantages from the GP-colocation with other GPs and/or other professionals.

Our study will therefore attempt to answer the following questions:

- What relationships are there between GP colocation and the range of services provided, the use of clinical governance tools and inter-professional collaboration?

- What are the relationships between GP colocation and the accessibility, comprehensiveness and continuity of care as perceived by their patients? 


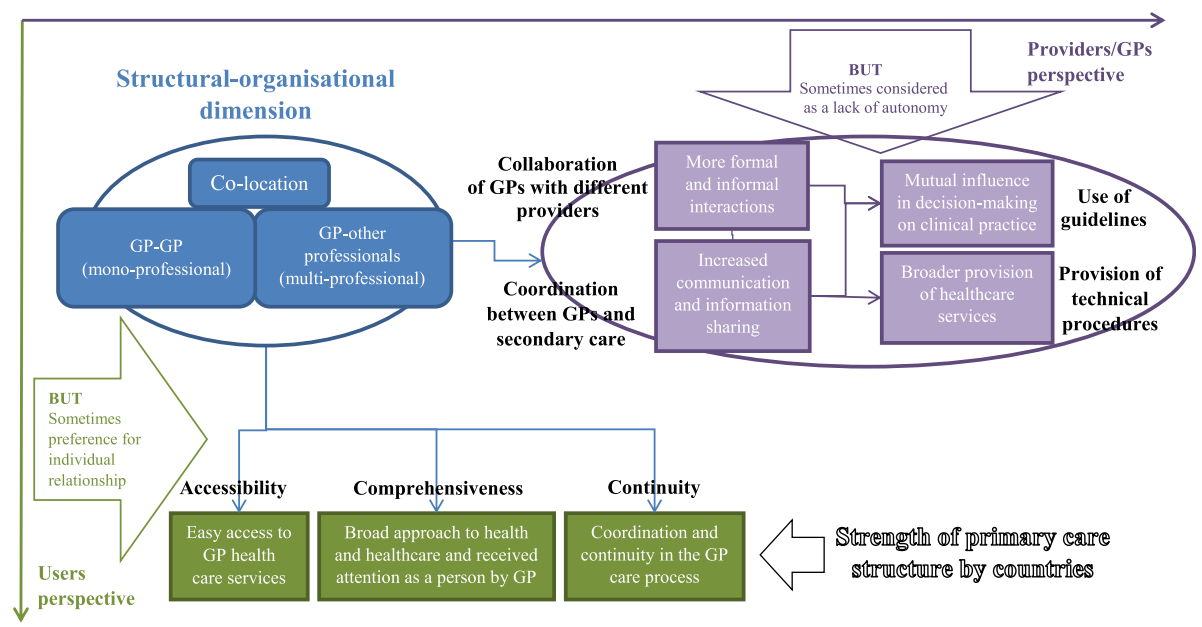

Fig. 1 Relationships between GP co-location and GPs' and patients' experiences: conceptual framework of the study

- Do the mono- and multi-professional co-location of GPs and the combination of these two dimensions relate differently to GP outcomes and patient experiences?

Mono-professional GP co-location is particularly interesting because, to the best of our knowledge, its role in terms of GP outcomes and patient experience has not yet been analysed. Regarding multi-professional GP co-location, we will also investigate the relationships between GP outcomes and patient experience and GPs co-located with nurses, other health professionals and social workers.

Finally, we consider the role of the strength of primary care at the national level $[30,31]$ in conditioning the relationships between GP co-location and patient experience, in fact a stronger primary care structure is associated with more accessible, continuous and comprehensive care [50].

Before presenting the methodological details, the following section overviews how GP co-location has functioned in the 34 countries involved in this study.

\section{Co-location in primary care: Some experiences in western countries}

The term co-location is used for the organisational strategy of grouping different professionals in the same facility, which in primary care particularly involves GPs, nurses, other health professionals (such as midwives, physiotherapists, dentists, pharmacists or even specialists of secondary care) and social workers.

Although Groenewegen et al. [22] do not refer explicitly to the concept of co-location, they observed a high variability in the number of professionals working with GPs within the same practice. Of the 34 countries we analysed, almost half (16) are characterised by GPs working with at least three professionals. The largest number of co-located professions with GPs are in Lithuania (8 other professions), Finland (7), Cyprus and Spain (6) and Iceland, Sweden and England (with 5 other professions).

All these countries, where a considerable level of GP co-location is quite widespread, are very different in terms of health system characteristics and primary care development (see Appendix 1). The co-location strategy does not seem to be related particularly to specific health system characteristics. Indeed, although the majority are countries with a tax-funded national health system, there are also transitional countries (Lithuania, Poland, Slovenia), where GPs are co-located in large polyclinics typical of their previous healthcare system, and one country with a social health insurance system (i.e. the Netherlands, with the longest experience of primary care centres with GPs, nurses, social workers, physiotherapists).

Although the majority of countries have strong primary care with GPs playing a gatekeeping role, the two with the largest GP practice (Cyprus with urban and rural health centres, and Iceland with primary care centres located throughout the country) have the weakest primary care system, according to the Primary Health Care Activity Monitor Europe study [30-33]. However, a significant association was observed between stronger primary care systems, in particular with a better developed primary care workforce and more comprehensive primary care processes, and larger primary care practices with more primary care professions [22].

The experiences of co-location are country dependent and it is difficult to summarize any 
common policies regulating their implementation. In Lithuania, GPs are co-located in primary care centres and polyclinics which often provide both primary and secondary outpatient services. Finnish primary health centres offer a broad range of primary health care services at the municipality level. In Spain, GPs work together with nurses, social workers, paediatricians, midwives, specialists, dentists, physiotherapists, with a formalised primary care multi-professional team. GP-led health centres in England have a more limited inter-professional collaboration without the presence of social workers. In Sweden primary care is provided in multidisciplinary teams, with at least one GP and one nurse, but often with social workers, psychologists and physiotherapists working at the primary health care centres. Medical homes in Australia and New Zealand promote the person-centred medical home (PCMH) model, with patients having an ongoing relationship with a particular doctor (who leads a multidisciplinary practice team) and primary care that is comprehensive, coordinated and accessible, with a focus on safety and quality.

The key common aspect of all these situations is that GPs and other professionals work together in the same facility, which constitutes the variable of interest to be explored in relation to the GPs' working methods and patient experiences.

\section{Methods}

We used data derived from the QUALICOPC study (Quality and Costs of Primary Care in Europe). In this study, cofunded by the European Commission, surveys were conducted among GPs and patients in 31 European countries (EU 27 except for France, along with FYR Macedonia, Iceland, Norway, Switzerland and Turkey) and three nonEuropean countries (Australia, Canada, New Zealand). The QUALICOPC study used nationally representative samples in the majority of countries. GPs and patients were surveyed with standardized questionnaires. One GP per practice was sampled. Target response was 220 GPs (75 in the four smallest countries). In every practice, nine patients filled in a Patient Experience questionnaire on the consultation that had just occurred. Ethical approval was acquired in accordance with the legal requirements in each country. Depending on the national requirements, written or oral informed consent was requested.

GPs were invited via letter, email or telephone and gave their consent to participate in the study. Patients were invited by the fieldworker or practice staff to complete a questionnaire. All participants were informed about the study and participation was voluntary [44]. A unique practice identification number anonymously linked GP responses to the responses of their patients, allowing for multi-level analyses of the data.

Data collection took place between October 2011 and December 2013. The GP questionnaire was filled in by 7183 GPs and the Patient Experience questionnaire by 61,931 patients (database version 4.1, June 2014). The age and gender of the participating GPs were compared to national statistics and the representativeness of these two variables was generally good [21]. Details regarding the study protocol and questionnaire development have been published elsewhere $[21,51,52]$.

\section{Independent variables concerning GP co-location}

The main explanatory factor included in this study is GP co-location which is defined as a GP located in the same primary care facility with other GPs and/or other professionals. GP co-location is measured by two dichotomised variables:

- GP alone or with other GPs, considered as monoprofessional GP co-location;

- GP(s) with at least one other health or social care professional, considered as multi-professional GP co-location.

The two variables were created on the basis of the answers to the GP questionnaire, which contained questions asking whether or not a GP works in the same practice/centre with other GPs, specialists and twelve types of other professionals.

We defined multi-professional GP co-location as GP(s) co-located with a nurse or another health professional (specialist, midwife, physiotherapist, dentist or pharmacist) or social worker. For the nursing role, we considered practice nurses, community nurses and nurse practitioners. If nurses worked with $\mathrm{GP}(\mathrm{s})$ without a secretary/receptionist and if they did not provide vaccinations, health information, do check-ups or minor clinical activities, they were not considered as playing a real nursing role, but as a substitute for a secretary/receptionist. The health professionals co-located with a GP are those providing specialised care, maternal care, rehabilitation, oral health care or pharmaceutical services and contribute to comprehensive health care delivery $[25,29,53]$. Finally, multi-professional GP co-location also takes into account the presence of a social worker, who facilitates the integration of the social and health domains in primary care $[16,26,56]$.

We investigated the association of the two different dimensions of GP co-location with GPs' and patients' experiences, both as a separate (additive) and joint effect (interaction). We also analysed the association between GPs' and patients' experiences and colocation of GP with specific professionals, such as 
nurses, other health professionals (specialists, midwives, physiotherapists, dentists or pharmacists) and social workers.

\section{Dependent variable: GPs' outcomes and patients' experiences}

We studied the relationships between GP co-location and both GPs' outcomes and patients' experience.

At the GP level, we explored four dependent variables that we hypothesised would be associated with GP co-location. They concern GP clinical practice, in terms of health care provision, clinical behaviour and inter-professional working. The following GP variables were included:

- provision of technical procedures (sum score of 10 procedures),

- use of guidelines (sum score in four areas: chronic heart failure, asthma, COPD, diabetes),

- collaboration with other providers (3 categories of meeting frequency of GPs with 10 types of primary care professionals);

- coordination between GPs and secondary care (3 categories of meeting frequency of GPs asking for advice from 10 different types of specialists).

All previous outcomes were measured through scales constructed through latent class multilevel analyses with items nested in GPs and in countries [52].

The other group of independent variables concerns the experiences of patients. We used scales measuring accessibility (5 questions on the access to GP practices concerning organisational aspects, such as for instance opening hours), comprehensiveness (2 questions on whether GPs represent the first contact for common health problems) and continuity of care with their GPs (3 questions on whether GPs have known the patient on a long-term basis). These scales were constructed through latent class multilevel analyses with items nested in patients, GPs and countries and these had been used in other studies to measure patient perceptions of GP quality [50].

\section{Statistical analysis}

To analyse the relationship between GP co-location and GP outcomes and patient experiences, a multilevel linear regression analysis was used, since all dependent variables can be treated as continuous variables considering the process used to build them. This study included 60,762 patients of GPs who had completed a questionnaire (7163 GPs).

When analysing outcome variables concerning GPs, the country represented the highest level and GP the lowest. A third level (patient) was included in the models analysing the patients' experiences.

In order to answer the three research questions, we performed four models for each dependent variable, both at the GP and patient levels. In the first two models, we explored the main effects of the two components of GP co-location separately (mono and multiprofessional). The results of these analyses are in the Appendix 3.

The third model focused on the interaction of the two variables concerning GP co-location. In this model, we found differences in the relationship with outcomes among four possible settings: 1) only one GP without other professionals (single-handed GP practice), 2) GP with only other GPs (i.e. no other types of professionals), 3) only one GP with other professionals and, 4) two or more GPs with other professionals (Tables 4 and 5). Finally, in the fourth model we considered the three sub-variables of multiprofessional GP co-location separately, in order to highlight the specific relationships between colocation with nurses, with other health professionals and with social workers and GP outcomes and patient experiences (results in the Appendix 3).

The interpretation of the results of the four models applied to the GP outcomes enabled us to answer the first research question, while the second research question was answered by the four models applied to the patient experiences. The analysis of differences in the relationships between GP colocation and GP outcomes and patient experience emerging from the comparison of the results among the four models enabled us to answer the third research question (Table 1).

All models were adjusted for GP covariates, such as sex, age and location of practice in urban/rural areas and involvement in disease management. Evening opening times of the GP practice and its location were considered as GP covariates in the adjusted model that analysed patients' experiences.

All the models concerning patients' experiences were also adjusted for patients' socio-demographic and health characteristics (sex, age, education, ethnicity, household income, self-reported health status and chronic conditions), the main reason for the visit to GPs (administrative vs health reason) and for having their 'own' doctor.

We reported the variances in the empty model, in the model with only the covariates, and in the model with the covariates plus the variables of interest (the combination of mono and multi-professional colocation).

As a sensitivity analysis, we tested whether the differences concerning the coordination with secondary care 
Table 1 Framework of the study methods

\begin{tabular}{|c|c|c|c|}
\hline \multicolumn{2}{|c|}{ Methods used to answer the research questions } & \multicolumn{2}{|l|}{ Dependent variables } \\
\hline Multilevel regression models & Independent variables & $\begin{array}{l}\text { GP outcomes } \\
\text { (4 variables) }\end{array}$ & $\begin{array}{l}\text { Patient experience } \\
\text { (3 variables) }\end{array}$ \\
\hline Model 1: Mono-professional co-location & Variable 1: GP with other GPs & \multirow{4}{*}{$\begin{array}{l}\text { First research question: } \\
\text { What relationships are } \\
\text { there between GP } \\
\text { co-location and the } \\
\text { range of services } \\
\text { provided, the use of } \\
\text { clinical governance } \\
\text { tools and } \\
\text { inter-professional } \\
\text { collaboration? }\end{array}$} & \multirow{4}{*}{$\begin{array}{l}\text { Second research question: } \\
\text { What are the relationships } \\
\text { between GP co-location } \\
\text { and the accessibility, } \\
\text { comprehensiveness and } \\
\text { continuity of care as } \\
\text { perceived by their patients? }\end{array}$} \\
\hline Model 2: Multi-professional co-location & Variable 2: GP with other professionals & & \\
\hline $\begin{array}{l}\text { Model 3: Interaction between } \\
\text { mono- and multi-professional } \\
\text { co-location }\end{array}$ & $\begin{array}{l}\text { Variable } 1 \times \text { Variable 2: } \\
\text { - Single-handed GP practice } \\
\text { - Two or more GPs without other } \\
\text { professionals } \\
\text { - One GP with other professionals } \\
\text { - Two or more GPs with other } \\
\text { professionals }\end{array}$ & & \\
\hline $\begin{array}{l}\text { Model 4: Details of GP co-location } \\
\text { with multi-professionals }\end{array}$ & $\begin{array}{l}\text { Variable } 2 \text { detailed: } \\
\text { - GP with nurse } \\
\text { - GP with other health professionals } \\
\text { - GP with social worker }\end{array}$ & & \\
\hline \multicolumn{2}{|c|}{$\begin{array}{l}\text { Comparison of the results between the four models in order to identify } \\
\text { differences in the relationships between independent variables and } \\
\text { dependent variables }\end{array}$} & \multicolumn{2}{|c|}{$\begin{array}{l}\text { Third research questions: } \\
\text { Do the mono- and multi-professional co-location of GPs and } \\
\text { the combination of these two dimensions relate differently } \\
\text { to GP outcomes and patient experiences? }\end{array}$} \\
\hline
\end{tabular}

were still present when removing GPs who were colocated with specialists. This kind of sensitivity analysis verifies the specific role of specialists in the relationship between GPs co-located with other professionals and integration with secondary care.

We used the GP outcome variables (such as the provision of technical procedures, use of guidelines, collaboration with other providers and coordination between GPs and secondary care) and transformed them into categorised variables to perform stratified analyses in order to verify whether they had an interaction effect with co-location on patient outcomes.

Finally, to obtain more information to answer the second research question, we explored the possible differences in the relationships between GP colocation and patient experience at the country level, by performing a stratified analysis of the models concerning patient outcomes based on the level of strength of the primary care structure in each country [30-32]. The strength of primary care systems at a national level was categorized in tertiles.

All analyses were performed using Stata 14.

\section{Results}

The median participation rate of GPs was 30\% [21] and the average response rate of patients was $74 \%$ [50]. Table 2 reports the GP co-location in all 34 countries. The tables show the distribution of each separate independent variable: GP co-location with other GPs and GP co-location with other professionals, with the details of GP co-location with nurses, other health professionals, and social workers. The table highlights a large variability in the distribution of independent variables.

Around half of the GPs work in the same practice/ centre with other GPs. There are only nine countries where more than $85 \%$ of GPs are co-located with other GPs, including Iceland, Norway and Sweden with almost all GPs working in a co-located setting. On the other hand, in Austria, Latvia and particularly Slovakia less than one GP in ten is co-located with other GPs.

Being co-located with at least one other professional is the most common situation of the GPs involved in the study. Only in Belgium, Italy, Luxemburg and Switzerland is this type of GP co-location found in less than $25 \%$ of all practices. In some countries all GPs are co-located with other professionals (Estonia, Iceland, Lithuania, Portugal, Spain, Sweden, England), and many others exceed $90 \%$.

Within multi-professional GP co-location, being in the same practice/centre with nurses is the most common, while only around one in three GPs are co-located with specialists, midwives, physiotherapists, dentists or pharmacists. Cyprus, Finland, Lithuania, Malta, Poland, Spain and England have the highest percentage of GPs co-located with other health professionals (around 75-85\%), while Belgium, Czech Republic, Denmark, Germany, Hungary, Italy, Latvia and Slovakia have the lowest proportions (below 10\%). Co-location of GPs with a social worker is even rarer (only 15\%), however there are countries where GPs never work in the same practice/centre with social workers (Czech Republic, Denmark, Germany, Turkey). Spain and Sweden are outsiders because their GPs are very often co-located 
Table 2 Distribution of the independent variables by country

\begin{tabular}{|c|c|c|c|c|c|}
\hline \multirow[t]{4}{*}{ Countries } & \multicolumn{5}{|l|}{ Type of GP co-location } \\
\hline & \multirow[t]{2}{*}{ GP with other GPs ${ }^{a}$} & \multicolumn{4}{|c|}{ GP with other professionals } \\
\hline & & At least one ${ }^{b}$ & Nurse & Health professional ${ }^{c}$ & Social worker \\
\hline & Practice (\%) $N=6880$ & Practice (\%) $N=7163$ & Practice (\%) N = 7051 & Practice (\%) $N=7163$ & Practice (\%) $N=7047$ \\
\hline Austria & 8.8 & 34.8 & 26.3 & 15.8 & 2.9 \\
\hline Belgium & 46.9 & 13.0 & 8.0 & 8.0 & 6.7 \\
\hline Bulgaria & 22.5 & 79.4 & 74.9 & 20.2 & 2.3 \\
\hline Cyprus & 85.9 & 91.6 & 91.3 & 88.7 & 18.8 \\
\hline Czech Republic & 11.0 & 95.9 & 96.3 & 5.5 & 0.0 \\
\hline Denmark & 71.6 & 80.2 & 81.0 & 5.7 & 0.5 \\
\hline Estonia & 31.0 & 100.0 & 99.2 & 20.2 & 1.6 \\
\hline Finland & 65.1 & 99.3 & 99.7 & 87.3 & 45.4 \\
\hline Germany & 38.2 & 27.3 & 22.7 & 6.3 & 0.0 \\
\hline Greece & 45.5 & 72.7 & 69.1 & 47.7 & 19.1 \\
\hline Hungary & 11.3 & 96.0 & 98.6 & 9.5 & 4.2 \\
\hline Iceland & 97.5 & 100.0 & 97.5 & 98.8 & 20.0 \\
\hline Ireland & 72.5 & 96.4 & 95.8 & 36.9 & 8.4 \\
\hline Italy & 51.6 & 22.5 & 19.4 & 8.7 & 2.0 \\
\hline Latvia & 9.8 & 99.5 & 99.5 & 9.6 & 3.7 \\
\hline Lithuania & 53.4 & 100.0 & 99.6 & 93.8 & 48.0 \\
\hline Luxembourg & 49.4 & 15.4 & 6.7 & 10.3 & 5.3 \\
\hline Malta & 54.4 & 75.7 & 58.6 & 72.9 & 6.9 \\
\hline Netherlands & 69.8 & 97.0 & 96.6 & 42.6 & 18.7 \\
\hline Norway & 99.0 & 54.0 & 40.4 & 26.8 & 1.5 \\
\hline Poland & 65.9 & 99.5 & 98.2 & 75.5 & 5.5 \\
\hline Portugal & $d$ & 100.0 & 100.0 & 19.4 & 42.6 \\
\hline Romania & 53.6 & 94.1 & 93.6 & 20.0 & 3.2 \\
\hline Slovakia & 3.2 & 91.4 & 91.3 & 5.0 & 1.4 \\
\hline Slovenia & 17.5 & 98.5 & 98.1 & 63.6 & 4.4 \\
\hline Spain & 94.6 & 100.0 & 99.3 & 83.1 & 77.5 \\
\hline Sweden & 99.0 & 100.0 & 100.0 & 55.7 & 69.1 \\
\hline Switzerland & 48.2 & 21.1 & 6.1 & 15.1 & 1.0 \\
\hline Turkey & 88.0 & 99.0 & 94.7 & 76.6 & 0.3 \\
\hline UK (England) & 92.9 & 100.0 & 100.0 & 78.1 & 3.0 \\
\hline Australia & 88.2 & 88.8 & 84.6 & 44.1 & 4.7 \\
\hline Canada & 79.7 & 69.7 & 60.2 & 37.9 & 21.8 \\
\hline New Zealand & 87.4 & 98.2 & 98.2 & 47.0 & 6.0 \\
\hline FYR Macedonia & 47.5 & 97.2 & 94.9 & 22.4 & 1.5 \\
\hline Average & 56.5 & 78.3 & 75.5 & 38.9 & 15.5 \\
\hline Weak PC countries & 36.2 & 78.6 & 75.2 & 32.4 & 6.0 \\
\hline Medium PC countries & 53.0 & 71.0 & 65.5 & 39.1 & 11.9 \\
\hline Strong PC countries & 72.3 & 84.9 & 82.3 & 42.9 & 23.2 \\
\hline
\end{tabular}

apercentage of the sampled GPs co-located with at least another GP, irrespective of whether other professionals are present or not

${ }^{\mathrm{b}}$ Percentage of the sampled GPs co-located with at least another professional (nurse, health professional - specialist, midwife, physiotherapist, dentist, pharmacist -, social worker), irrespective of whether other GPs are present or not

${ }^{\mathrm{c}}$ Health professionals include specialists, midwives, physiotherapists, dentists, pharmacists

${ }^{d}$ All values of this question are recoded into missing due to a translation error in the GP questionnaire for Portugal 
with a social worker, and in Lithuania, Finland and Portugal this is also quite common.

Countries with weak primary care $[30,31]$ have fewer GPs co-located with other GPs, other health professionals and social workers, while they have a higher percentage of GPs co-located with nurses compared to countries with a medium primary care structure. Countries with strong primary care most often show GP colocation (Table 2).

Considering the interaction of the two independent variables (Table 3), mono-professional GP co-location and single-handed GP practice are on the whole less common (respectively $9.6 \%$ and $12.9 \%$ ) than multiprofessional GP co-location with only one GP (30.7\%) and with more GPs (46.9\%).

Detailed figures of GP outcome variables are provided in the Appendix 2, while the other patient outcome variables have been reported in other studies [50].

\section{GP outcomes}

The multilevel regression analysis (Table 4) revealed that the majority of variation in GP outcomes is at the GP level, except for the provision of technical procedures which is mainly related to the country level (intraclass correlation, ICC, 69.2\%). Coordination with secondary care and use of guidelines have the lowest ICC at the country level (respectively $13.4 \%$ and $20.6 \%$ ), however, these are still relatively high ICCs.
All types of GP co-location are positively associated with the provision of technical procedures. The strongest relationship is when a GP is co-located with other GPs and other professionals $(p<0.001$, Table 4 second column). When GPs are co-located with nurses, they are more likely to provide technical procedures compared to GPs co-located with other professionals $(p<0.001$, see Appendix 3$)$.

The use of guidelines is not associated with mono or multi-professional GP co-location (Table 4 third column), except when considering the multiprofessional details as separate independent variables (see Appendix 3).

Compared with single-handed GP practices, mono and multi-professional GP co-location GP are associated with more collaboration with different providers (respectively $p<0.05$ and $p<0.001$ ), particularly when a GP is co-located with other GPs and other professionals $(p<0.001$, Table 4 fourth column). More collaboration with other providers is also related to GP co-located with nurses, other health professionals and social workers, particularly GP co-location with a social worker $(p<0.001$, see Appendix 3$)$.

Compared with single handed GP practices, all colocated settings (only mono-professional, only multiprofessional and mono and multi-professional) are more coordinated with secondary care $(p<0.001$, Table 4, fifth column). GPs who are co-located with other professionals, in particular with specialists, midwives, physiotherapists, dentists or pharmacists, are more coordinated with secondary care $(p<0.01$,

Table 3 Interaction between the two independent variables

\begin{tabular}{|c|c|c|c|c|}
\hline \multirow[t]{2}{*}{ Types of GP co-location } & & \multicolumn{2}{|c|}{ GP with other professionals (multi-professional co-location) } & \multirow[t]{2}{*}{ Total } \\
\hline & & No & Yes & \\
\hline \multirow{10}{*}{$\begin{array}{l}\mathrm{GP} \text { with other GPs } \\
\text { (mono-professional colocation) }\end{array}$} & \multirow[t]{5}{*}{ No } & 1) Single-handed GP practice & 3) One GP with other professionals & GP alone \\
\hline & & 886 & 2109 & 2995 \\
\hline & & $12.9 \%$ & $30.7 \%$ & $43.5 \%$ (cell) \\
\hline & & $29.6 \%$ & $70.4 \%$ & $100.0 \%$ (row) \\
\hline & & $57.2 \%$ & $39.6 \%$ & $43.5 \%$ (col) \\
\hline & \multirow[t]{5}{*}{ Yes } & 2) More GPs without other professionals & 4) More GPs with other professionals & GP with other GPs \\
\hline & & 662 & 3223 & 3885 \\
\hline & & $9.6 \%$ & $46.9 \%$ & $56.5 \%$ (cell) \\
\hline & & $17.0 \%$ & $83.0 \%$ & $100.0 \%$ (row) \\
\hline & & $42.8 \%$ & $60.4 \%$ & $56.5 \%(\mathrm{col})$ \\
\hline \multirow[t]{5}{*}{ Total } & & GP without other professionals & GP with at least one professional & Total \\
\hline & & 1589 & 5291 & 6880 \\
\hline & & $22.5 \%$ (cell) & $77.5 \%$ (cell) & $100.0 \%$ \\
\hline & & $22.5 \%$ (row) & $77.5 \%$ (row) & $100.0 \%$ \\
\hline & & $100.0 \%$ (col) & $100.0 \%$ (col) & $100.0 \%$ \\
\hline
\end{tabular}


Table 4 Relationships between GP co-location and GP outcomes

\begin{tabular}{|c|c|c|c|c|c|c|c|c|}
\hline \multirow{2}{*}{$\begin{array}{l}\text { Multilevel models } \\
\left({ }^{*} p<0.05 ;{ }^{* *} p<0.01 ;{ }^{* *} p<0.001\right)\end{array}$} & \multicolumn{2}{|c|}{$\begin{array}{l}\text { Provision of technical } \\
\text { procedures }^{a}\end{array}$} & \multicolumn{2}{|c|}{$\begin{array}{l}\text { Use of } \\
\text { guidelines }^{a}\end{array}$} & \multicolumn{2}{|c|}{$\begin{array}{l}\text { Collaboration with different } \\
\text { providers }^{\mathrm{a}}\end{array}$} & \multicolumn{2}{|c|}{$\begin{array}{l}\text { Coordination with } \\
\text { secondary care }\end{array}$} \\
\hline & Coeff. & S.E. & Coeff. & S.E. & Coeff. & S.E. & Coeff. & S.E. \\
\hline \multicolumn{9}{|l|}{ Single-handed GP practice (ref) } \\
\hline - More GPs without other professionals & $0.153^{* * *}$ & 0.023 & 0.021 & 0.013 & $0.033^{*}$ & 0.013 & $0.090^{* * *}$ & 0.024 \\
\hline - One GP with other professionals & $0.146^{* * *}$ & 0.022 & -0.003 & 0.012 & $0.106^{* * *}$ & 0.013 & $0.108^{* * *}$ & 0.022 \\
\hline - More GPs with other professionals & $0.200^{* * *}$ & 0.021 & -0.001 & 0.012 & $0.143^{* * *}$ & 0.012 & $0.080^{* * *}$ & 0.022 \\
\hline Random part / Variance in full model & Var. & S.E. & Var. & S.E. & Var. & S.E. & Var. & S.E. \\
\hline Country level & 0.415 & 0.100 & 0.012 & 0.003 & 0.023 & 0.006 & 0.028 & 0.007 \\
\hline GP level & 0.182 & 0.003 & 0.053 & 0.001 & 0.057 & 0.001 & 0.184 & 0.003 \\
\hline Variance in empty model & Var. & S.E. & Var. & S.E. & Var. & S.E. & Var. & S.E. \\
\hline Country level & 0.452 & 0.110 & 0.014 & 0.004 & 0.025 & 0.006 & 0.029 & 0.007 \\
\hline GP level & 0.201 & 0.003 & 0.054 & 0.001 & 0.060 & 0.001 & 0.186 & 0.003 \\
\hline Variance in model only with covariates & Var. & S.E. & Var. & S.E. & Var. & S.E. & Var. & S.E. \\
\hline Country level & 0.409 & 0.099 & 0.012 & 0.003 & 0.022 & 0.005 & 0.029 & 0.007 \\
\hline GP level & 0.185 & 0.003 & 0.053 & 0.001 & 0.057 & 0.001 & 0.182 & 0.003 \\
\hline
\end{tabular}

${ }^{a}$ Covariates GP level: sex, age, urbanisation, involvement in disease management

see Appendix 3). These results are confirmed also after excluding GPs co-located with specialists (results not in tables) and therefore the positive association between GP co-location and integration with secondary care is not due only to the presence of specialists in the same practice/centre with GPs.

\section{Patient experience}

We found that some areas of patient experience are strongly clustered at the country and GP levels. The intraclass correlation of both levels ranges from $60 \%$ for continuity of care to around $97 \%$ for accessibility and comprehensiveness (Table 5).

Table 5 Relationships between GP co-location and patient experience

\begin{tabular}{|c|c|c|c|c|c|c|}
\hline \multirow{2}{*}{$\begin{array}{l}\text { Multilevel models } \\
\left({ }^{*} p<0.05 ;{ }^{* *} p<0.01 ;{ }^{* * *} p<0.001\right) \\
\text { Fixed part }\end{array}$} & \multicolumn{2}{|c|}{ Accessibility ${ }^{a, b}$} & \multicolumn{2}{|c|}{ Continuity of care $\mathrm{e}^{\mathrm{a}, \mathrm{b}}$} & \multicolumn{2}{|c|}{ Comprehensiveness of care $\mathrm{e}^{\mathrm{a}, \mathrm{b}}$} \\
\hline & Coeff. & S.E. & Coeff. & S.E. & Coeff. & S.E. \\
\hline \multicolumn{7}{|l|}{ Single-handed GP practice (ref) } \\
\hline - More GPs without other professionals & -0.359 & 0.366 & -0.656 & 0.476 & -0.825 & 0.587 \\
\hline - One GP with other professionals & -0.688 & 0.354 & $-1.352^{* *}$ & 0.460 & $-1.439^{*}$ & 0.567 \\
\hline - More GPs with other professionals & $-0.804^{*}$ & 0.340 & $-1.433^{* *}$ & 0.443 & -1.047 & 0.545 \\
\hline Random part & Var. & S.E. & Var. & S.E. & Var. & S.E. \\
\hline Country level & 32.312 & 8.061 & 80.276 & 19.940 & 86.434 & 21.970 \\
\hline GP level & 44.180 & 0.797 & 64.054 & 1.351 & 114.423 & 2.050 \\
\hline Patient level & 3.232 & 0.021 & 97.611 & 0.634 & 5.724 & 0.037 \\
\hline Variance in empty model & Var. & S.E. & Var. & S.E. & Var. & S.E. \\
\hline Country level & 35.020 & 8.586 & 100.427 & 24.559 & 96.802 & 23.721 \\
\hline GP level & 46.587 & 0.804 & 72.022 & 1.438 & 114.199 & 1.965 \\
\hline Patient level & 3.376 & 0.021 & 103.538 & 0.635 & 5.642 & 0.035 \\
\hline Variance in model only with covariates & Var. & S.E. & Var. & S.E. & Var. & S.E. \\
\hline Country level & 32.441 & 7.970 & 79.997 & 19.598 & 91.415 & 22.433 \\
\hline GP level & 44.812 & 0.788 & 62.665 & 1.295 & 112.172 & 1.968 \\
\hline Patient level & 3.286 & 0.021 & 95.480 & 0.607 & 5.605 & 0.036 \\
\hline
\end{tabular}

${ }^{a}$ Covariates patient level: sex, age, education, household income, ethnicity, self-reported health status, main reason for visit, personal GP, chronic conditions

${ }^{\mathrm{b} C o v a r i a t e s ~ G P ~ l e v e l: ~ s e x, ~ a g e, ~ u r b a n i s a t i o n, ~ i n v o l v e m e n t ~ i n ~ d i s e a s e ~ m a n a g e m e n t, ~ e v e n i n g ~ o p e n ~ t i m e ~ f o r ~ G P ~ p r a c t i c e, ~ u r b a n i s a t i o n ~}$ 
When GPs are co-located with other GPs and other professionals, patients experience less accessibility compared to patients of single-handed GP practices $(p<0.05$, Table 5 second column). Also in the separate models, multi-professional GP co-location continues to be negatively associated with accessibility ( $\mathrm{p}$ $<0.05$, see Appendix 3). Co-location of a GP with social workers has a negative relationship with this patient experience $(p<0.01$, see Appendix 3$)$.

Compared to patients of GPs working in singlehanded practices, patients perceive less continuity of care when their GPs are co-located only with other professionals or with other GPs and other professionals $(p<0.01$, Table 5 third column). This negative association with continuity of care is also present as one of the main effects / as the main effect of GP co-location in a multiprofessional setting $(p<0.01$, see Appendix 3), and in practices where GPs are co-located with nurses, patients experience even less continuity of care $(p<0.001$, see Appendix 3).

Compared with patients of GPs working in singlehanded GP practices, patients perceive their GPs who are co-located only in multi-professional settings to provide less comprehensive care $(p<0.05$, Table 5 fourth column). Comprehensiveness of care has the strongest negative relationship of GP colocation of all the dimensions of patient experiences analysed.

When we introduced GP outcome variables as covariates into the models analysing patient outcomes, the association between GP co-location and patient outcomes did not change significantly (results not in tables). This was particularly the case with variables such as provision of technical procedures, collaboration with different providers and coordination between GPs and secondary care which are positively related with GP co-location. The direction and strength of relationships which were statistically significant were confirmed. Only the negative associations with accessibility and comprehensiveness of care were slightly reduced when controlling for coordination with secondary care. When these models were stratified by the categorised GP outcome variables, the results were no longer interpretable.

The stratification by strength of primary care at a country level highlighted that in countries with a weak level of primary care, GP co-location is associated with worse patient experience, particularly when GPs are co-located in a multi-professional setting. In countries with a stronger level of primary care (medium and high level), the associations between GP co-location and patient experiences are not significant or, when significant, have a positive direction. In countries with a medium primary care structure, when GPs are co-located with other professionals and/or other GPs, patients perceive a better accessibility to GP care compared to a singlehanded GP practice (Table 6).

\section{Discussion}

This study reveals the relationships between GP colocation with other GPs and/or other professionals and outcomes at the GP level and patient experiences. The results highlight a positive association between GP co-location and GP outcomes, in terms of more technical procedures, and in terms of more collaboration with other primary and secondary care professionals. Conversely, GP co-location was negatively associated with some patient experiences, particularly in countries with a weak primary care, while in the other countries GP co-location was not associated or positively associated with patient outcomes.

The largest share of variability is at the GP level for almost all the GP outcomes, except for provision of technical procedures. The variations in patient perceptions of accessibility and comprehensiveness of care is due mainly to the GP and country levels, while continuity of care is more related to variability at the patient level. The country influence may play a different role in influencing the outcomes analysed from patient perspectives.

\section{Summary and interpretation of the relationships between GP co-location and GP outcomes}

Almost all our hypotheses on GP outcomes concerning our first research question were confirmed. On the whole, from the point of view of GPs themselves, GP co-location has positive associations with a wider range of services provided, higher use of clinical governance tools and more inter-professional collaboration. The higher provision of technical procedures associated with GP co-location, particularly when they are with nurses, counteracts the notion that GPs have been gradually abandoning the technical aspects of medicine to specialists [59]. A recent study in the Netherlands found that patients prefer to substitute specialist care with GP care mainly for certain medical procedures (e.g. follow-up treatments and noncomplex treatments) [58], and thus the broader provision of procedures by a GP co-located with other professionals can be seen as one aspect of a more responsive care approach. Indeed, more comprehensive primary care gives patients access to healthcare services at the primary care level for which they would usually have to go to other providers (in other locations). 
Table $\mathbf{6}$ Interaction between the level of strength of primary care structure and GP co-location on patient experiences

\begin{tabular}{|c|c|c|c|c|c|c|}
\hline \multirow{3}{*}{$\begin{array}{l}\text { Stratified multilevel models } \\
\left({ }^{*} p<0.05 ;{ }^{* *} p<0.01 ;{ }^{* * *} p<0.001\right) \\
\text { Countries with weak } P C \text { structure }\end{array}$} & \multicolumn{2}{|c|}{ Accessibility } & \multicolumn{2}{|c|}{ Continuity of care } & \multicolumn{2}{|c|}{ Comprehensiveness of care } \\
\hline & \multicolumn{2}{|c|}{$N .=14,973$} & \multicolumn{2}{|c|}{$N .=14,920$} & \multicolumn{2}{|c|}{$N .=14,917$} \\
\hline & Coeff. & S.E. & Coeff. & S.E. & Coeff. & S.E. \\
\hline \multicolumn{7}{|l|}{ Single-handed GP practice (ref) } \\
\hline - More GPs without other professionals & -0.766 & 0.918 & -0.425 & 1.359 & 0.770 & 1.369 \\
\hline - One GP with other professionals & $-2.637^{* * *}$ & 0.671 & $-2.681^{* *}$ & 0.994 & $-2.269^{*}$ & 1.000 \\
\hline - More GPs with other professionals & $-2.760^{* * *}$ & 0.709 & $-4.749^{* * *}$ & 1.051 & $-2.558^{*}$ & 1.057 \\
\hline \multirow[t]{2}{*}{ Countries with medium PC structure } & \multicolumn{2}{|c|}{$N .=19,188$} & \multicolumn{2}{|c|}{$N .=19.134$} & \multicolumn{2}{|c|}{$N .=19,054$} \\
\hline & Coeff. & S.E. & Coeff. & S.E. & Coeff. & S.E. \\
\hline \multicolumn{7}{|l|}{ Single-handed GP practice (ref) } \\
\hline - More GPs without other professionals & 0.927 & 0.482 & -0.306 & 0.707 & -1.175 & 0.850 \\
\hline - One GP with other professionals & 0.822 & 0.526 & -0.423 & 0.775 & -0.139 & 0.928 \\
\hline - More GPs with other professionals & $1.076^{*}$ & 0.517 & 0.610 & 0.763 & -0.446 & 0.912 \\
\hline \multirow[t]{2}{*}{ Countries with strong PC structure } & \multicolumn{2}{|c|}{$N .=19,830$} & \multicolumn{2}{|c|}{$N .=19,733$} & \multicolumn{2}{|c|}{$N .=19,648$} \\
\hline & Coeff. & S.E. & Coeff. & S.E. & Coeff. & S.E. \\
\hline \multicolumn{7}{|l|}{ Single-handed GP practice (ref) } \\
\hline - More GPs without other professionals & -0.922 & 0.649 & 0.147 & 0.534 & -0.877 & 1.039 \\
\hline - One GP with other professionals & 0.205 & 0.670 & 0.129 & 0.547 & -1.835 & 1.072 \\
\hline - More GPs with other professionals & -0.566 & 0.593 & -0.016 & 0.485 & -0.101 & 0.919 \\
\hline
\end{tabular}

This study highlights that GP co-location also has positive relationships with the collaboration with other professionals, confirming that physical proximity intensifies interactions and consequently informal and formal communication and knowledge exchange $[17,18]$. GP co-location thus seems to be a first step to overcoming professional barriers and facilitating the consolidation of teamwork [15, 42, 49].

Co-located GPs tend to work more in coordination with secondary care which may be seen as positive in reducing fragmentation in healthcare pathways and ensuring a closer inter-professional cooperation [46]. The increased exchange of advice observed between GPs and specialists goes beyond the colocation of GPs with specialists. It therefore seems that co-location in itself involves organisational changes that then improve the connections between primary and secondary care, thus leading to a better coordination of patient care. However, this closer collaboration between GPs and specialists can be interpreted differently in different countries. Indeed, where specialists are employed by public health services, the increased collaboration with GPs is seen mainly in terms of a potential improvement in the appropriateness and integration of healthcare. On the other hand, where specialists are private professionals, the increased exchange of advice with GPs might be seen as a risk of encouraging more specialist care visits.

We found less strong evidence that co-located GPs use more clinical governance tools. The weak association of GP co-location with the use of guidelines does not seem to confirm the mutual influence of colocated professionals on the uptake of clinical governance tools, which was instead found by de Jong [13] in terms of mutual control in clinical practice. In any case, in completing the questionnaire, GPs may have been influenced by the differences in clinical guidelines in different countries [37].

\section{Summary and interpretation of the relationships between GP co-location and patient experience}

Concerning the second research question, our hypotheses were almost completely refuted since we found that patients of co-located GPs did not perceive a better quality of care. Indeed, despite the general positive relationships between GP colocation and GP outcomes, GP co-location has a negative relationship with patient experiences in terms of accessibility, continuity and comprehensiveness of care.

These results can be interpreted in two ways. Although corresponding to improved healthcare service delivery from the providers' perspective, GP co- 
location is not associated with improved patient experiences, because patients perceive better quality care when they are treated in smaller practices where they have an individual relationship with their own GP [10, 2]. An alternative interpretation is that the observed differences in GP outcomes due to co-location may not yet have led to effective teamwork, due to the challenges related to interprofessional collaboration, such as difficulties in overcoming barriers and conflicts or defining roles and common objectives [34, 41, 45]. In fact, another study underlined the importance of a multidisciplinary team combined with GP co-location in increasing patient satisfaction [6]. Both interpretations are in line with the discrepancy of perspectives between providers and users that Lloyd and Wait highlighted [38] in providing a definition of integrated care. The authors reported that users and providers may disagree as to whether or not a healthcare experience is really integrated. In this case and contrary to our hypothesis, GPs and patients do not experience GP co-location in the same way, maybe because the advantages of GP co-location for the former are not as important for the latter.

The results change when we take into account the differences among countries related to the strength of their primary care structure. Indeed, in countries with a medium or strong primary care, GP co-location is not associated with patient experiences or there are signs of positive associations with some patient experiences. At the same time in countries with a weaker primary care structure, GP co-location is related to very negative experiences from the patients' perspective. Therefore, there is an interaction effect between GP co-location and the PC strength at the country level. This may be related to the different organisational models of GP co-location in different countries, from simple polyclinics to more integrated primary care centres, which may play a different role in affecting patient experience. In countries with a weak primary care, the organisational models of GP colocation may be implemented without a clear idea of the integration of services and professionals. Therefore patients perceived a lower quality of care in these settings compared to single-handed GP practices. Kringos et al. highlighted that teamwork and multidisciplinary collaboration have been poorly addressed in European primary care, especially in countries with weak primary care systems [33]. Not only do professionals need training to improve multidisciplinary collaboration, patients may also have difficulty in navigating larger facilities, where they deal with many different providers. In order to improve the patient experience, it may be necessary for larger facilities to be organised in a way that guarantees the continuity of care to patients.
Summary and interpretation of the different relationships of mono- and multi-professional co-location of GPs and GP outcomes and patient experience

In order to answer the third research question, we focused on the differences in the relationships between the different components of GP co-location and GP outcomes and patient experiences. Mono-professional colocation has a less strong association with GP outcomes, while multi-professional co-location has a stronger association with GP outcomes but is negatively associated, or not associated at all, with patient experience.

Compared with single-handed GP practices, GPs co-located with other GPs and professionals, which constitute the most complex form of GP co-location, has the best impact on GP outcomes, while one GP with other professionals represents a very negative co-located setting in terms of patient experience, particularly regarding continuity and comprehensiveness of care.

Regarding GP outcomes, the provision of technical procedures is more strongly associated with the colocation of GPs with nurses. The collaboration with other providers has a stronger association with the co-location of GPs with social workers, while coordination with secondary care is mostly associated with the co-location of GPs with other health professionals, such as specialists, midwives, physiotherapists, dentists and pharmacists.

Regarding patient experiences, co-location of GPs with nurses has the strongest negative association with continuity of care, maybe because in this setting, the nurses are the first point of contact and play the role of primary caregiver in the relationship with patients. In fact, a Cochrane systematic review [35] reported that nurses tended to provide longer consultations than GPs and to take responsibility for the ongoing management of patients with particular chronic conditions. Therefore, when GPs are colocated with nurses, the GPs themselves may be less informed about the medical history or conditions in which patients live. Co-location of GPs with other health professionals has no relationship with patient experience, while co-location of GPs with social workers has a negative association with accessibility. These results can be explained by considering that firstly, the co-location of GPs with social workers is not very common and may also be more related to larger health centres with more limited accessibility.

\section{Strengths and limitations of the study}

One major strength of our study is that it explores the relationships of GP co-location both with GP outcomes and patient experiences, providing evidence concerning the process and final outcomes of 
delivery changes in primary care through GP colocation. Other studies have included the analysis of the different perspectives related to GPs and patients, but with other approaches. Indeed, such studies have focused on GPs' and patients' perspectives regarding specific diseases [47] or concerning the quality of primary care $[28,43]$. In these cases, the attention is on the juxtaposition between the clinical perspective and that of patients, focused more on the personal aspects of an illness, or between the professional and lay opinions in terms of what is valued in primary care.

In contrast, our study explored the GPs' and patients' perspectives in relation to different topics that are relevant for GPs and patients themselves. For GPs, we focused on the range of services provided, the use of clinical governance tools and interprofessional collaboration. For patients, we focused on the accessibility, comprehensiveness and continuity of care as perceived by the patients themselves. For both groups and their related topics of interest, we explored the correlation of these outcomes with a structural and organisational dimension of health services delivery (i.e. co-location of GPs in mono or multiprofessionals settings).

The differences in the findings between the GPs' and patients' perspectives can be interpreted according to the Donabedian model [14], which focuses on the structure, process and outcomes of healthcare. According to this model, GP co-location can be considered as a structural factor of health services delivery, the topics which interest GPs are the process, whereas the topics of interest for patients are the final outcomes of the health services delivery. Therefore, the positive process (in terms of more technical procedures performed in GP practices, as well as more collaboration of GPs with other primary and secondary care professionals) due to the structural input of GP-colocation does not necessarily correspond to the final positive outcomes (in terms of more the accessibility, comprehensiveness and continuity of care perceived by patients). Indeed, the positive results of GP-colocation as perceived by GPs do not relate to positive results for patients, at least in the countries with a weak primary care, where the structural input of GP-colocation for health services delivery is probably characterised differently compared to countries with strong primary care.

An additional strength of the study is that the large number of countries involved enabled us to differentiate between the patient, practice and country levels and to look at the differences among countries based on their strength of primary care structure.
Our study also has limitations. GP co-location cannot be distinguished in terms of different organisational models and it has not been characterised according to the different composition of co-located teams. There is no information on the actual cooperation between co-located professionals, or on whether patients have actually experienced the interprofessional joint working in GPs co-location settings. Therefore, we cannot connect the structural and organisational dimension with professional integration. Moreover, considering that we used data from an international survey, GPs and patients from different countries may interpret the questions differently, also because of potential discrepancies related to different types of health systems among countries. As noted in another study on GP practice using the same data [22], some terms may have a different connotation from one country to another, in spite of the rigorous translation procedure implemented. Finally, GPs who are co-located with other GPs and/or other professionals may have consciously chosen this type of care setting, and therefore may be more biased towards co-location. This potential bias is perhaps less relevant for patients, as their freedom of choice for a specific practice may be influenced by the different regulatory and normative context existing in different countries, as well by the actual availability of different practices near the place they live.

\section{Conclusions}

This article has shown that GP co-location is associated with a broader provision of health care services in a primary care setting and with more collaboration between GPs and other primary and secondary care professionals. In addition GP co-location is mostly related to negative patient experiences, however this relationship is conditioned by the strength of primary care structure at the country level. It is only in countries with weak primary care that patients perceived a worse quality of care in co-located services compared with single-handed GP practices.

Considering the high variability among countries of the diffusion of GP co-location, which probably also represents a different interest in and approach to this organisational strategy in primary care in different countries, further research should focus on specific models through which GP co-location with other professionals is organized. The organisational characteristics of GP co-location could thus be identified, as well as the kind of support from policies to colocated settings, which may consolidate the positive process of collaboration among different professionals and facilitate a positive patient experience. 


\section{Appendix 1}

The table shows for each country involved in the study the median number of extra professions in GP practice (apart from GPs), the model of healthcare system, the role of GP as gatekeeper, the overall primary care system strength.

Table 7 Data on health systems characteristics of the 34 countries involved in the study

\begin{tabular}{|c|c|c|c|c|}
\hline Countries & $\begin{array}{l}\text { Median number of extra professions } \\
\text { in GP practice (apart from GPs) [22] }\end{array}$ & Model of healthcare system ${ }^{a}$ & $\begin{array}{l}\text { Role of GP as } \\
\text { gatekeeper }\end{array}$ & $\begin{array}{l}\text { Overall Primary Care } \\
\text { system strength [30-33] }\end{array}$ \\
\hline Austria & 1 & Social health insurance (Bismarck) & No & Weak \\
\hline Belgium & 0 & Social health insurance (Bismarck) & No & Strong \\
\hline Bulgaria & 1 & $\begin{array}{l}\text { Mixed model: tax-funded and social health } \\
\text { insurance }\end{array}$ & Yes & Weak \\
\hline Cyprus & 6 & Mixed model: tax-funded and private insurance & No, but planned & Weak \\
\hline $\begin{array}{l}\text { Czech } \\
\text { Republic }\end{array}$ & 1 & Social health insurance (Bismarck) & Yes, partially & Medium \\
\hline Denmark & 2 & Tax-funded (Beveridge) & Yes & Strong \\
\hline Estonia & 2 & Social health insurance (Bismarck) & Yes, partially & Strong \\
\hline Finland & 7 & Tax-funded (Beveridge) & Yes, partially & Strong \\
\hline Germany & 1 & Social health insurance (Bismarck) & No & Medium \\
\hline Greece & 2 & Tax-funded (Beveridge) & No & Weak \\
\hline Hungary & 1 & Social health insurance (Bismarck) & Yes, partially & Weak \\
\hline Iceland & 5 & Tax-funded (Beveridge) & Yes, partially & Weak \\
\hline Ireland & 3 & Tax-funded (Beveridge) & Yes & Weak \\
\hline Italy & 1 & Tax-funded (Beveridge) & Yes & Medium \\
\hline Latvia & 2 & $\begin{array}{l}\text { Tax-funded, but with high out-of-pocket } \\
\text { payments }\end{array}$ & Yes & Medium \\
\hline Lithuania & 8 & Transitional with National health insurance & Yes & Strong \\
\hline Luxembourg & 1 & Social health insurance (Bismarck) & No & Weak \\
\hline Malta & 3 & Tax-funded (Beveridge) & Yes & Weak \\
\hline Netherlands & 3 & Social health insurance (Bismarck) & Yes & Strong \\
\hline Norway & 1 & Tax-funded (Beveridge) & Yes & Medium \\
\hline Poland & 4 & Transitional with National health insurance & Yes & Medium \\
\hline Portugal & 3 & Tax-funded (Beveridge) & Yes & Strong \\
\hline Romania & 1 & Transitional with Social health insurance & Yes & Medium \\
\hline Slovakia & 1 & Social health insurance (Bismarck) & Yes, partially & Weak \\
\hline Slovenia & 4 & Transitional with Social health insurance & Yes & Strong \\
\hline Spain & 6 & Tax-funded (Beveridge) & Yes & Strong \\
\hline Sweden & 5 & Tax-funded (Beveridge) & Yes, partially & Medium \\
\hline Switzerland & 1 & Social health insurance (Bismarck) & No, but planned & Medium \\
\hline Turkey & 2 & Social health insurance (Bismarck) & No & Weak \\
\hline UK (England) & 5 & Tax-funded (Beveridge) & Yes & Strong \\
\hline Australia & 4 & Tax-funded (Beveridge) & Yes & Strong \\
\hline Canada & 3 & Tax-funded (Beveridge) & Yes & Strong \\
\hline New Zealand & 4 & Tax-funded (Beveridge) & Yes & Strong \\
\hline $\begin{array}{l}\text { FYR } \\
\text { Macedonia }\end{array}$ & 1 & Social health insurance (Bismarck) & Yes & Medium \\
\hline
\end{tabular}

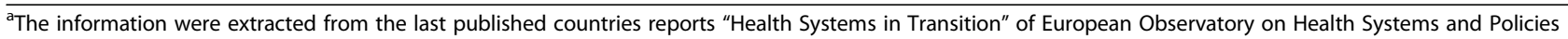




\section{Appendix 2}

The table shows for each country the mean and standard deviation of the dependent variables at the GP level, such as the provision of technical procedures, use of guidelines, collaboration with different providers, coordination with secondary care

Table 8 Distribution of dependent variables at the GP level by country

\begin{tabular}{|c|c|c|c|c|}
\hline Countries & $\begin{array}{l}\text { Provision of technical procedures }^{a} \\
N=7136 \\
\text { Mean (SD) }\end{array}$ & $\begin{array}{l}\text { Use of guidelines } \\
N=7127 \\
\text { Mean (SD) }\end{array}$ & $\begin{array}{l}\text { Collaboration with different providers } \\
N=7145 \\
\text { Mean (SD) }\end{array}$ & $\begin{array}{l}\text { Coordination with secondary care }{ }^{d} \\
N=7108 \\
\text { Mean (SD) }\end{array}$ \\
\hline Austria & $2.062(0.568)$ & $0.843(0.271)$ & $1.716(0.256)$ & $1.721(0.419)$ \\
\hline Belgium & $2.373(0.499)$ & $0.899(0.197)$ & $1.875(0.279)$ & $1.704(0.522)$ \\
\hline Bulgaria & $1.762(0.410)$ & $0.747(0.323)$ & $2.078(0.302)$ & $1.940(0.554)$ \\
\hline Cyprus & $1.260(0.199)$ & $0.516(0.393)$ & $2.050(0.289)$ & $1.541(0.490)$ \\
\hline Czech Republic & $1.396(0.291)$ & $0.838(0.249)$ & $1.832(0.229)$ & $1.657(0.396)$ \\
\hline Denmark & $2.538(0.452)$ & $0.923(0.143)$ & $1.560(0.184)$ & $1.638(0.357)$ \\
\hline Estonia & $1.551(0.437)$ & $0.309(0.183)$ & $1.964(0.218)$ & $1.605(0.386)$ \\
\hline Finland & $3.312(0.481)$ & $0.958(0.114)$ & $2.103(0.195)$ & $1.918(0.394)$ \\
\hline Germany & $1.832(0.464)$ & $0.920(0.186)$ & $1.576(0.232)$ & $1.797(0.409)$ \\
\hline Greece & $2.428(0.457)$ & $0.905(0.187)$ & $2.090(0.244)$ & $1.734(0.406)$ \\
\hline Hungary & $1.366(0.328)$ & $0.698(0.347)$ & $2.037(0.235)$ & $1.452(0.344)$ \\
\hline Iceland & $2.887(0.502)$ & $0.780(0.295)$ & $2.064(0.197)$ & $1.927(0.465)$ \\
\hline Ireland & $2.680(0.551)$ & $0.875(0.203)$ & $1.990(0.225)$ & $1.492(0.350)$ \\
\hline Italy & $1.392(0.306)$ & $0.869(0.228)$ & $1.698(0.246)$ & $1.570(0.431)$ \\
\hline Latvia & $1.426(0.303)$ & $0.921(0.182)$ & $2.075(0.226)$ & $1.869(0.424)$ \\
\hline Lithuania & $1.277(0.297)$ & $0.879(0.152)$ & $2.056(0.252)$ & $1.669(0.453)$ \\
\hline Luxembourg & $2.081(0.471)$ & $0.874(0.263)$ & $1.681(0.306)$ & $1.723(0.438)$ \\
\hline Malta & $2.203(0.469)$ & $0.864(0.244)$ & $1.907(0.252)$ & $1.551(0.450)$ \\
\hline Netherlands & $3.287(0.391)$ & $0.959(0.112)$ & $2.121(0.220)$ & $2.062(0.452)$ \\
\hline Norway & $3.123(0.442)$ & $0.898(0.188)$ & $1.853(0.222)$ & $2.011(0.419)$ \\
\hline Poland & $1.325(0.313)$ & $0.891(0.237)$ & $2.097(0.267)$ & $1.495(0.471)$ \\
\hline Portugal & $1.782(0.422)$ & $0.908(0.178)$ & $1.978(0.207)$ & $1.359(0.309)$ \\
\hline Romania & $1.428(0.360)$ & $0.615(0.367)$ & $1.882(0.274)$ & $1.582(0.483)$ \\
\hline Slovakia & $1.300(0.346)$ & $0.488(0.332)$ & $1.806(0.243)$ & $1.625(0.483)$ \\
\hline Slovenia & $1.669(0.465)$ & $0.959(0.102)$ & $2.024(0.196)$ & $1.558(0.353)$ \\
\hline Spain & $2.212(0.488)$ & $0.938(0.156)$ & $1.735(0.240)$ & $1.479(0.427)$ \\
\hline Sweden & $2.990(0.367)$ & $0.919(0.198)$ & $2.123(0.242)$ & $1.663(0.370)$ \\
\hline Switzerland & $2.580(0.587)$ & $0.794(0.315)$ & $1.716(0.241)$ & $1.882(0.370)$ \\
\hline Turkey & $1.749(0.452)$ & $0.654(0.376)$ & $1.802(0.253)$ & $1.463(0.406)$ \\
\hline UK (England) & $2.642(0.505)$ & $0.989(0.016)$ & $2.077(0.198)$ & $1.683(0.409)$ \\
\hline Australia & $2.887(0.590)$ & $0.805(0.309)$ & $1.824(0.256)$ & $1.614(0.386)$ \\
\hline Canada & $2.648(0.606)$ & $0.922(0.161)$ & $1.971(0.296)$ & $1.942(0.492)$ \\
\hline New Zealand & $3.220(0.488)$ & $0.792(0.303)$ & $1.900(0.211)$ & $1.690(0.380)$ \\
\hline FYR Macedonia & $1.277(0.216)$ & $0.924(0.205)$ & $1.900(0.246)$ & $1.726(0.470)$ \\
\hline Average & $2.134(0.794)$ & $0.854(0.260)$ & $1.909(0.291)$ & $1.695(0.467)$ \\
\hline Weak PC countries & $1.795(0.671)$ & $0.766(0.320)$ & $1.950(0.294)$ & $1.684(0.471)$ \\
\hline Medium PC countries & $2.156(0.818)$ & $0.876(0.234)$ & $1.907(0.288)$ & $1.725(0.458)$ \\
\hline Strong PC countries & $2.337(0.771)$ & $0.890(0.222)$ & $1.885(0.289)$ & $1.675(0.472)$ \\
\hline
\end{tabular}

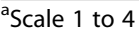

bsale 0 to 1

'Scale 1 to 3

dScale 1 to 3 


\section{Appendix 3}

The tables show the results of the multilevel linear regression analysis performed in the study, with the details for each model:

- empty model

- model with only covariates

- model 1 exploring the main effects of the mono-professional GP co-location

- model 2 exploring the main effects of the multi-professional GP co-location

- model 3 exploring the interaction of mono e multi-professional GP co-location

- model 4 exploring the main effect of the three sub-variables of multi-professional GP co-location, such as co-location with nurses, with other health professionals and with social workers

In particular the first table shows the results of the multilevel models analysing the relationships of GP co-location and GP outcomes and the second table shows the results of the multilevel models analysing the relationships of GP co-location and patient experiences.

Table 9 Detailed results of the multilevel models of GP co-location (mono-professional - model 1, multi-professional - model 2, interaction between mono and multi-professional - model 3, details of multi-professional - model 4) and GP outcomes

\begin{tabular}{|c|c|c|c|c|c|c|c|c|c|}
\hline \multicolumn{2}{|c|}{$\begin{array}{l}\text { Multilevel models } \\
\left({ }^{*} p<0.05 ;{ }^{* *} p<0.01 ;{ }^{* *} p<0.001\right)\end{array}$} & \multicolumn{2}{|c|}{$\begin{array}{l}\text { Provision of } \\
\text { technical } \\
\text { procedures }^{\text {a }}\end{array}$} & \multicolumn{2}{|c|}{$\begin{array}{l}\text { Use of } \\
\text { guidelines }^{a}\end{array}$} & \multicolumn{2}{|c|}{$\begin{array}{l}\text { Collaboration with } \\
\text { different providers }\end{array}$} & \multicolumn{2}{|c|}{$\begin{array}{l}\text { Integration with } \\
\text { secondary care }\end{array}$} \\
\hline & & \multicolumn{2}{|c|}{$N .=7136$} & \multicolumn{2}{|c|}{$N .=7127$} & \multicolumn{2}{|c|}{$N .=7145$} & \multicolumn{2}{|c|}{$N .=7108$} \\
\hline \multirow[t]{9}{*}{ Empty model } & Fixed part & Coeff. & S.E. & Coeff. & S.E. & Coeff. & S.E. & Coeff. & S.E. \\
\hline & Intercept & $2.116^{* * *}$ & 0.115 & $0.843^{* * *}$ & 0.021 & $1.916^{* * *}$ & 0.027 & $1.687^{* * *}$ & 0.030 \\
\hline & Random part & Var. & S.E. & Var. & S.E. & Var. & S.E. & Var. & S.E. \\
\hline & Country level & 0.452 & 0.110 & 0.014 & 0.004 & 0.025 & 0.006 & 0.029 & 0.007 \\
\hline & GP level & 0.201 & 0.003 & 0.054 & 0.001 & 0.060 & 0.001 & 0.186 & 0.003 \\
\hline & ICC & & & & & & & & \\
\hline & Country & $69.2 \%$ & & $20.6 \%$ & & $29.6 \%$ & & $13.4 \%$ & \\
\hline & GP & $30.8 \%$ & & $79.4 \%$ & & $70.4 \%$ & & $86.6 \%$ & \\
\hline & & \multicolumn{2}{|c|}{$N .=6934$} & \multicolumn{2}{|c|}{$N .=6940$} & \multicolumn{2}{|c|}{$N .=6944$} & \multicolumn{2}{|c|}{$N .=6908$} \\
\hline \multirow[t]{9}{*}{ Model only covariates } & Fixed part & Coeff. & S.E. & Coeff. & S.E. & Coeff. & S.E. & Coeff. & S.E. \\
\hline & Intercept & $2.034^{* * *}$ & 0.110 & $0.790^{* * *}$ & 0.020 & $1.873^{* * *}$ & 0.029 & $1.593^{* * *}$ & 0.033 \\
\hline & Random part & Var. & S.E. & Var. & S.E. & Var. & S.E. & Var. & S.E. \\
\hline & Country level & 0.409 & 0.099 & 0.012 & 0.003 & 0.027 & 0.007 & 0.029 & 0.007 \\
\hline & GP level & 0.185 & 0.003 & 0.053 & 0.001 & 0.058 & 0.001 & 0.182 & 0.003 \\
\hline & ICC & & & & & & & & \\
\hline & Country & $68.8 \%$ & & $18.8 \%$ & & $31.9 \%$ & & $13.9 \%$ & \\
\hline & GP & $31.2 \%$ & & $81.2 \%$ & & $68.1 \%$ & & $86.1 \%$ & \\
\hline & & \multicolumn{2}{|c|}{$N .=6655$} & \multicolumn{2}{|c|}{$N .=6660$} & \multicolumn{2}{|c|}{$N .=6663$} & \multicolumn{2}{|c|}{$N .=6628$} \\
\hline \multirow[t]{5}{*}{ MODEL 1 (variable 1) } & Fixed part & Coeff. & S.E. & Coeff. & S.E. & Coeff. & S.E. & Coeff. & S.E. \\
\hline & Intercept & $1.985^{* * *}$ & 0.111 & $0.782^{* * *}$ & 0.021 & $1.844^{* * *}$ & 0.031 & $1.600^{* * *}$ & 0.033 \\
\hline & GP co-located with other GP & $0.093^{* * *}$ & 0.013 & 0.007 & 0.007 & $0.047^{* * *}$ & 0.007 & 0.011 & 0.013 \\
\hline & Random part & Var. & S.E. & Var. & S.E. & Var. & S.E. & Var. & S.E. \\
\hline & Country level & 0.396 & 0.098 & 0.012 & 0.003 & 0.028 & 0.007 & 0.028 & 0.007 \\
\hline
\end{tabular}


Table 9 Detailed results of the multilevel models of GP co-location (mono-professional - model 1, multi-professional - model 2, interaction between mono and multi-professional - model 3, details of multi-professional - model 4) and GP outcomes (Continued)

\begin{tabular}{|c|c|c|c|c|c|c|c|c|c|}
\hline \multicolumn{2}{|c|}{$\begin{array}{l}\text { Multilevel models } \\
\left({ }^{*} p<0.05 ;{ }^{* *} p<0.01 ;{ }^{* * *} p<0.001\right)\end{array}$} & \multicolumn{2}{|c|}{$\begin{array}{l}\text { Provision of } \\
\text { technical } \\
\text { procedures }\end{array}$} & \multicolumn{2}{|c|}{$\begin{array}{l}\text { Use of } \\
\text { guidelines }\end{array}$} & \multicolumn{2}{|c|}{$\begin{array}{l}\text { Collaboration with } \\
\text { different providers }\end{array}$} & \multicolumn{2}{|c|}{$\begin{array}{l}\text { Integration with } \\
\text { secondary care }\end{array}$} \\
\hline & GP level & 0.184 & 0.003 & 0.053 & 0.001 & 0.058 & 0.001 & 0.185 & 0.003 \\
\hline & ICC & & & & & & & & \\
\hline & Country & $68.3 \%$ & & $18.7 \%$ & & $32.6 \%$ & & $13.0 \%$ & \\
\hline & GP & $31.7 \%$ & & $81.3 \%$ & & $67.4 \%$ & & $87.0 \%$ & \\
\hline & & $N .=6$ & & $N .=6$ & 931 & $N .=$ & & $N .=6$ & \\
\hline \multirow[t]{10}{*}{ MODEL 2 (variable 2) } & Fixed part & Coeff. & S.E. & Coeff. & S.E. & Coeff. & S.E. & Coeff. & S.E. \\
\hline & Intercept & $1.944^{* * *}$ & 0.112 & $0.799^{* * *}$ & 0.022 & $1.782^{* * *}$ & 0.028 & $1.553^{* * *}$ & 0.036 \\
\hline & GP co-located with other professional & $0.113^{* * *}$ & 0.018 & -0.011 & 0.009 & $0.117^{* * *}$ & 0.010 & $0.052^{* *}$ & 0.018 \\
\hline & Random part & Var. & S.E. & Var. & S.E. & Var. & S.E. & Var. & S.E. \\
\hline & Country level & 0.411 & 0.100 & 0.012 & 0.003 & 0.022 & 0.005 & 0.031 & 0.008 \\
\hline & GP level & 0.184 & 0.003 & 0.053 & 0.001 & 0.057 & 0.001 & 0.182 & 0.003 \\
\hline & ICC & & & & & & & & \\
\hline & Country & $69.1 \%$ & & $18.6 \%$ & & $27.6 \%$ & & $14.5 \%$ & \\
\hline & GP & $30.9 \%$ & & $81.4 \%$ & & $72.4 \%$ & & $85.5 \%$ & \\
\hline & & \multicolumn{2}{|c|}{$N .=6655$} & \multicolumn{2}{|c|}{$N .=6660$} & \multicolumn{2}{|c|}{$N .=6663$} & \multicolumn{2}{|c|}{$N .=6628$} \\
\hline \multirow[t]{13}{*}{ MODEL 3 (interaction) } & Fixed part & Coeff. & S.E. & Coeff. & S.E. & Coeff. & S.E. & Coeff. & S.E. \\
\hline & Intercept & $1.885^{* * *}$ & 0.113 & $0.788^{* * *}$ & 0.023 & $1.768^{* * *}$ & 0.029 & $1.528^{* * *}$ & 0.037 \\
\hline & Single-handed GP practice (ref) & & & & & & & & \\
\hline & - More GPs without other professionals & $0.153^{* * *}$ & 0.023 & 0.021 & 0.013 & $0.033^{*}$ & 0.013 & $0.090^{* * *}$ & 0.024 \\
\hline & - One GP with other professionals & $0.146^{* * *}$ & 0.022 & -0.003 & 0.012 & $0.106^{* * *}$ & 0.013 & $0.108^{* * *}$ & 0.022 \\
\hline & - More GPs with other professionals & $0.200^{* * *}$ & 0.021 & -0.001 & 0.012 & $0.143^{* * *}$ & 0.012 & $0.080^{* * *}$ & 0.022 \\
\hline & Random part & Var. & S.E. & Var. & S.E. & Var. & S.E. & Var. & S.E. \\
\hline & Country level & 0.415 & 0.100 & 0.012 & 0.003 & 0.023 & 0.006 & 0.028 & 0.007 \\
\hline & GP level & 0.182 & 0.003 & 0.053 & 0.001 & 0.057 & 0.001 & 0.184 & 0.003 \\
\hline & ICC & & & & & & & & \\
\hline & Country & $69.0 \%$ & & $18.5 \%$ & & $28.5 \%$ & & $13.4 \%$ & \\
\hline & GP & $31.0 \%$ & & $81.5 \%$ & & $71.5 \%$ & & $86.6 \%$ & \\
\hline & & $N .=6813$ & & $N .=6819$ & & $N .=6823$ & & $N .=6787$ & \\
\hline \multirow{11}{*}{$\begin{array}{l}\text { MODEL } 4 \\
\text { (var } 2 \text { details) }\end{array}$} & Fixed part & Coeff. & S.E. & Coeff. & S.E. & Coeff. & S.E. & Coeff. & S.E. \\
\hline & Intercept & $1.931^{* * *}$ & 0.111 & $0.787^{* * *}$ & 0.022 & $1.756^{* * *}$ & 0.026 & $1.544^{* * *}$ & 0.036 \\
\hline & GP with nurse & $0.103^{* * *}$ & 0.018 & -0.004 & 0.010 & $0.093^{* * *}$ & 0.010 & $0.037^{*}$ & 0.018 \\
\hline & GP with other health professional & $0.060^{* *}$ & 0.014 & $0.003^{*}$ & 0.007 & $0.079^{* * *}$ & 0.008 & $0.043^{* *}$ & 0.014 \\
\hline & GP with social worker & $0.043^{* *}$ & 0.018 & 0.007 & 0.010 & $0.118^{* * *}$ & 0.010 & 0.022 & 0.018 \\
\hline & Random part & Var. & S.E. & Var. & S.E. & Var. & S.E. & Var. & S.E. \\
\hline & Country level & 0.406 & 0.099 & 0.012 & 0.003 & 0.019 & 0.005 & 0.031 & 0.008 \\
\hline & GP level & 0.182 & 0.003 & 0.053 & 0.001 & 0.054 & 0.001 & 0.181 & 0.003 \\
\hline & ICC & & & & & & & & \\
\hline & Country & $69.0 \%$ & & $18.7 \%$ & & $26.3 \%$ & & $14.7 \%$ & \\
\hline & GP & $31.0 \%$ & & $81.3 \%$ & & $73.6 \%$ & & $85.3 \%$ & \\
\hline
\end{tabular}


Table 10 Detailed results of the multilevel models of GP co-location (mono-professional - model 1, multi-professional - model 2, interaction between mono and multi-professional - model 3, details of multi-professional - model 4) and patient experience

\begin{tabular}{|c|c|c|c|c|c|c|c|}
\hline \multicolumn{2}{|c|}{$\begin{array}{l}\text { Multilevel models } \\
\left({ }^{*} p<0.05 ;{ }^{* *} p<0.01 ;{ }^{* * *} p<0.001\right)\end{array}$} & \multicolumn{2}{|c|}{ Accessibility $^{\mathrm{a}, \mathrm{b}}$} & \multicolumn{2}{|c|}{ Continuity of care $\mathrm{e}^{\mathrm{a}, \mathrm{b}}$} & \multicolumn{2}{|c|}{ Comprehensiveness of care ${ }^{a, b}$} \\
\hline & & \multicolumn{2}{|c|}{$N .=60,309$} & \multicolumn{2}{|c|}{$N .=60,069$} & \multicolumn{2}{|c|}{$N .=59,851$} \\
\hline \multirow[t]{10}{*}{ Empty model } & Fixed part & Coeff. & S.E. & Coeff. & S.E. & Coeff. & S.E. \\
\hline & Intercept & $85.141^{* * *}$ & 1.019 & $90.439^{* * *}$ & 1.723 & $68.934^{* * *}$ & 1.694 \\
\hline & Random part & Var. & S.E. & Var. & S.E. & Var. & S.E. \\
\hline & Country level & 35.020 & 8.586 & 100.427 & 24.559 & 96.802 & 23.721 \\
\hline & GP level & 46.587 & 0.804 & 72.022 & 1.438 & 114.199 & 1.965 \\
\hline & Patient level & 3.376 & 0.021 & 103.538 & 0.635 & 5.642 & 0.035 \\
\hline & \multicolumn{7}{|l|}{ ICC } \\
\hline & Country & \multicolumn{2}{|l|}{$41.2 \%$} & \multicolumn{2}{|l|}{$36.4 \%$} & \multicolumn{2}{|l|}{$44.7 \%$} \\
\hline & GP & \multicolumn{2}{|l|}{$54.8 \%$} & \multicolumn{2}{|l|}{$26.1 \%$} & \multicolumn{2}{|l|}{$52.7 \%$} \\
\hline & & \multicolumn{2}{|c|}{$N .=56,217$} & \multicolumn{2}{|c|}{$N .=56,049$} & \multicolumn{2}{|c|}{$N_{.}=55,879$} \\
\hline \multirow[t]{10}{*}{ Model only covariates } & Fixed part & Coeff. & S.E. & Coeff. & S.E. & Coeff. & S.E. \\
\hline & Intercept & $82.920^{* * *}$ & 1.011 & $77.096^{* * *}$ & 1.599 & $65.754^{* * *}$ & 1.690 \\
\hline & Random part & Var. & S.E. & Var. & S.E. & Var. & S.E. \\
\hline & Country level & 32.441 & 7.970 & 79.997 & 19.598 & 91.415 & 22.433 \\
\hline & GP level & 44.812 & 0.788 & 62.665 & 1.295 & 112.172 & 1.968 \\
\hline & Patient level & 3.286 & 0.021 & 95.480 & 0.607 & 5.605 & 0.036 \\
\hline & ICC & & & & & & \\
\hline & Country & $40.3 \%$ & & $33.6 \%$ & & $43.7 \%$ & \\
\hline & GP & $55.6 \%$ & & $26.3 \%$ & & $53.6 \%$ & \\
\hline & & \multicolumn{2}{|c|}{$N .=53,951$} & \multicolumn{2}{|c|}{$N .=53,787$} & \multicolumn{2}{|c|}{$N .=53,619$} \\
\hline \multirow{11}{*}{$\begin{array}{l}\text { MODEL } 1 \\
\text { (variable 1) }\end{array}$} & Fixed part & Coeff. & S.E. & Coeff. & S.E. & Coeff. & S.E. \\
\hline & Intercept & $83.261^{* * *}$ & 1.037 & $77.016^{* * *}$ & 1.636 & $65.399 * * *$ & 1.698 \\
\hline & GP co-located with other GP & -0.251 & 0.212 & -0.385 & 0.276 & -0.070 & 0.341 \\
\hline & Random part & Var. & S.E. & Var. & S.E. & Var. & S.E. \\
\hline & Country level & 32.718 & 8.158 & 80.441 & 20.008 & 87.367 & 21.790 \\
\hline & GP level & 44.408 & 0.798 & 64.169 & 1.353 & 114.536 & 2.052 \\
\hline & Patient level & 3.232 & 0.021 & 97.611 & 0.634 & 5.724 & 0.037 \\
\hline & ICC & & & & & & \\
\hline & Country & $40.7 \%$ & & $33.2 \%$ & & $42.1 \%$ & \\
\hline & GP & $55.3 \%$ & & $26.5 \%$ & & $55.2 \%$ & \\
\hline & & \multicolumn{2}{|c|}{$N .=56,165$} & \multicolumn{2}{|c|}{$N .=55,998$} & $N .=$ & \\
\hline MODEL 2 & Fixed part & Coeff. & S.E. & Coeff. & S.E. & Coeff. & S.E. \\
\hline 2) & Intercept & $83.379^{* * *}$ & 1.027 & 77. $974^{* * *}$ & 1.620 & $66.293^{* * *}$ & 1.746 \\
\hline & GP co-located with other professional & -0.593 & 0.278 & $-1.101^{* *}$ & 0.357 & -0.713 & 0.440 \\
\hline & Random part & Var. & S.E. & Var. & S.E. & Var. & S.E. \\
\hline & Country level & 32.004 & 7.867 & 79.720 & 19.531 & 90.662 & 22.556 \\
\hline & GP level & 44.898 & 0.787 & 62.542 & 1.293 & 112.126 & 1.968 \\
\hline & Patient level & 3.286 & 0.021 & 95.379 & 0.607 & 5.607 & 0.036 \\
\hline & ICC & & & & & & \\
\hline
\end{tabular}


Table 10 Detailed results of the multilevel models of GP co-location (mono-professional - model 1, multi-professional - model 2, interaction between mono and multi-professional - model 3, details of multi-professional - model 4) and patient experience (Continued)

\begin{tabular}{|c|c|c|c|c|c|c|c|}
\hline \multicolumn{2}{|c|}{$\begin{array}{l}\text { Multilevel models } \\
\left({ }^{*} p<0.05 ;{ }^{* *} p<0.01 ;{ }^{* * *} p<0.001\right)\end{array}$} & \multicolumn{2}{|c|}{ Accessibility ${ }^{a, b}$} & \multicolumn{2}{|c|}{ Continuity of care $e^{a, b}$} & \multicolumn{2}{|c|}{ Comprehensiveness of care ${ }^{\mathrm{a}, \mathrm{b}}$} \\
\hline & Country & $40.0 \%$ & & $33.5 \%$ & & $43.5 \%$ & \\
\hline & GP & $55.9 \%$ & & $26.3 \%$ & & $53.8 \%$ & \\
\hline & & \multicolumn{2}{|c|}{$N .=53,951$} & \multicolumn{2}{|c|}{$N .=53,787$} & \multicolumn{2}{|c|}{$N .=53,619$} \\
\hline \multirow[t]{14}{*}{ MODEL 3 (interaction) } & Fixed part & Coeff. & S.E. & Coeff. & S.E. & Coeff. & S.E. \\
\hline & Intercept & $83.727^{* * *}$ & 1.057 & $77.935^{* * *}$ & 1.663 & $66.345^{* * *}$ & 1.724 \\
\hline & \multicolumn{7}{|l|}{ Single-handed GP practice (ref) } \\
\hline & - More GPs without other professionals & -0.359 & 0.366 & -0.656 & 0.476 & -0.825 & 0.587 \\
\hline & - One GP with other professionals & -0.688 & 0.354 & $-1.352^{* *}$ & 0.460 & $-1.439^{*}$ & 0.567 \\
\hline & - More GPs with other professionals & $-0.804^{*}$ & 0.340 & $-1.433^{* *}$ & 0.443 & -1.047 & 0.545 \\
\hline & Random part & Var. & S.E. & Var. & S.E. & Var. & S.E. \\
\hline & Country level & 32.312 & 8.061 & 80.276 & 19.940 & 86.434 & 21.970 \\
\hline & GP level & 44.180 & 0.797 & 64.054 & 1.351 & 114.423 & 2.050 \\
\hline & Patient level & 3.232 & 0.021 & 97.611 & 0.634 & 5.724 & 0.037 \\
\hline & \multicolumn{7}{|l|}{ ICC } \\
\hline & Country & \multicolumn{2}{|l|}{$40.4 \%$} & \multicolumn{2}{|l|}{$33.2 \%$} & \multicolumn{2}{|l|}{$41.8 \%$} \\
\hline & GP & \multicolumn{2}{|l|}{$55.5 \%$} & \multicolumn{2}{|l|}{$26.5 \%$} & \multicolumn{2}{|l|}{$55.4 \%$} \\
\hline & & \multicolumn{2}{|c|}{$N .=55,251$} & \multicolumn{2}{|c|}{$N .=55,086$} & \multicolumn{2}{|c|}{$N .=54,916$} \\
\hline \multirow{12}{*}{$\begin{array}{l}\text { MODEL } 4 \\
\text { (var } 2 \text { details) }\end{array}$} & Fixed part & Coeff. & S.E. & Coeff. & S.E. & Coeff. & S.E. \\
\hline & Intercept & $83.452^{* * *}$ & 1.027 & $78.161^{* * *}$ & 1.680 & $66.322^{* * *}$ & 1.731 \\
\hline & GP with nurse & -0.563 & 0.289 & $-1.386^{* * *}$ & 0.370 & -0.860 & 0.456 \\
\hline & GP with other health professional & -0.025 & 0.227 & 0.286 & 0.290 & -0.067 & 0.358 \\
\hline & GP with social worker & $-0.818^{* *}$ & 0.304 & -0.273 & 0.388 & 0.475 & 0.480 \\
\hline & Random part & Var. & S.E. & Var. & S.E. & Var. & S.E. \\
\hline & Country level & 31.915 & 7.825 & 86.316 & 21.155 & 92.273 & 22.657 \\
\hline & GP level & 44.895 & 0.797 & 61.916 & 1.292 & 112.850 & 1.980 \\
\hline & Patient level & 3.290 & 0.021 & 95.114 & 0.610 & 5.611 & 0.036 \\
\hline & \multicolumn{7}{|l|}{ ICC } \\
\hline & Country & $39.8 \%$ & & $35.5 \%$ & & $44.0 \%$ & \\
\hline & GP & $56.0 \%$ & & $25.4 \%$ & & $53.3 \%$ & \\
\hline
\end{tabular}

${ }^{a}$ Covariates patient level: sex, age, education, household income, ethnicity, self-reported health status, main reason for visit, personal GP, chronic conditions ${ }^{b}$ Covariates GP level: sex, age, urbanisation, involvement in disease management, evening open time for GP practice, urbanisation

Abbreviations

GP: General practitioner; QUALICOPC: Quality and Costs of Primary Care in Europe

\section{Acknowledgments}

We thank partners in the QUALICOPC project; J De Maeseneer, E De Ryck, L Hanssens, A Van Pottelberge, S Willems (Belgium); S Greß, (Germany); G Capitani, S De Rosis, AM Murante, S Nuti, C Seghieri, M Vainieri (Italy); M Van den Berg, D Kringos, T Van Loenen (the Netherlands); D Rotar Pavlič, I Švab (Slovenia). We thank the coordinators of the data collection in each country: $L$ Jorm, I McRae (Australia); K Hoffmann, M Maier (Austria); P Salchev (Bulgaria); W Wodchis, W Hogg (Canada); G Samoutis (Cyprus); B Seifert, N Šrámková (Czech Republic); J Reinholdt Jensen, P Vedsted (Denmark); M Lember, K Pölluste (Estonia); E Kosunen (Finland); C Lionis (Greece); I Rurik (Hungary); J
Heimisdóttir, O Thorgeirsson (Iceland); C Collins (Ireland); G Ticmane (Latvia); S Macinskas (Lithuania); M Aubart, J Leners, R Stein (Luxembourg); G Bezzina, P Sciortino (Malta); T Ashton, R McNeill (New Zealand); T Bjerve Eide, H Melbye (Norway); M Oleszczyk, A Windak (Poland); L Pisco (Portugal), D Farcasanu (Romania); E Jurgova (Slovakia); T Dedeu (Spain); C Björkelund, T Faresjö (Sweden); T Bisschoff, N Senn (Switzerland); K Stavric (The former Yugoslav Republic of Macedonia); M Akman (Turkey); C Sirdifield, N Siriwardena (United Kingdom).

\section{Funding}

The study is part of the QUALICOPC (Quality and Costs of Primary Care in Europe) project, co-funded by the European Commission under the Seventh Framework Programme (FP7/2007-2013) under grant agreement 242141. 


\section{Availability of data and materials}

Data from the QUALICOPC project will be made available in a data repository. The selection of data used for this study can be shared by contacting the corresponding author.

\section{Authors' contributions}

$M B, W S, S B$ and $P G$ designed the study and formulated the research question. WS and PG coordinated the implementation of the QUALICOPC study, whose data were used in this study. MB analysed the data and wrote the draft manuscript. MB, WS, SB, SH and PG interpreted and discussed the results, revised and approved the final manuscript.

\section{Ethics approval and consent to participate}

Ethical approval was acquired in accordance with the legal requirements in each country. Depending on the national requirements, written or oral informed consent was requested [21].

In the following table we report an overview of the ethics committees in each country.

\begin{tabular}{|c|c|}
\hline Country & Ethics committee \\
\hline Australia & $\begin{array}{l}\text { The Australian National University (ANU) Human Research } \\
\text { Ethics Committee. } \\
\text { University of Western Sydney Human Research Ethics } \\
\text { Committee. } \\
\text { The Royal Australian College of General Practitioners (RACGP) } \\
\text { National Research and Evaluation Ethics Committee. }\end{array}$ \\
\hline Austria & Ethics committee of the Medical University of Vienna. \\
\hline Belgium & University Hospital Ghent - Commission for Medical Ethics. \\
\hline Bulgaria & $\begin{array}{l}\text { The coordinator sent an official letter to the Ministry of } \\
\text { Health which gave consent and support for the survey. The } \\
\text { coordinator confirmed that there is no statutory requirement } \\
\text { for ethical approval for this study. }\end{array}$ \\
\hline Canada & 10 different ethics boards ${ }^{a}$. \\
\hline Cyprus & National Bioethical Committee of Cyprus. \\
\hline $\begin{array}{l}\text { Czech } \\
\text { Republic }\end{array}$ & $\begin{array}{l}\text { General University Hospital linked to the First Faculty of } \\
\text { Medicine, Charles University in Prague. }\end{array}$ \\
\hline Denmark & $\begin{array}{l}\text { The coordinator confirmed that there is no statutory } \\
\text { requirement for ethical approval for this study. }\end{array}$ \\
\hline Estonia & $\begin{array}{l}\text { The national coordinator consulted with the Ethics Review } \\
\text { Committee on Human Research of the University of Tartu. It } \\
\text { was confirmed that there is no statutory requirement for } \\
\text { ethical approval for this study. }\end{array}$ \\
\hline Finland & The ethical committee of Pirkanmaa Hospital District. \\
\hline Germany & Ethics Commision of the "Landesärtzenkammer Hessen". \\
\hline Greece & Bioethical committees of seventy hospitals. \\
\hline Hungary & National Ethical Committee. \\
\hline Iceland & $\begin{array}{l}\text { The Icelandic Bioethics Committee. A national committee } \\
\text { under the Ministry of Welfare. }\end{array}$ \\
\hline Ireland & $\begin{array}{l}\text { Irish College of General Practitioners Research Ethics } \\
\text { Committee - National Committee. }\end{array}$ \\
\hline Italy & $\begin{array}{l}\text { At Local Health Authorities level. Approval was requested } \\
\text { from LHA Ethical Committees. }\end{array}$ \\
\hline Latvia & Latvian Physicians Association Board of Certification. \\
\hline Lithuania & Kauno Regionus Biomedicininu Tyrimu Etikos Komitetas. \\
\hline Luxembourg & National committee of Research Ethic (CNER) in Luxembourg. \\
\hline $\begin{array}{l}\text { FYR } \\
\text { Macedonia }\end{array}$ & Medical Faculty Skopje, R.Macedonia. \\
\hline Malta & University of Malta Research Ethics Committee. \\
\hline
\end{tabular}

(Continued)

Netherlands The ethics committee of VU Medisch Centrum confirmed via an official letter that the research is outside the scope of the WMO (Medical Research Involving Human Subjects Act).

New Zealand Northern regional committee (Northern Y) for the nationally coordinated Health and Disability Ethics Committees (HDEC).

Norway The coordinator confirmed that there is no statutory requirement for ethical approval for this study.

Poland Bioethics approval of Jagiellonian University

Portugal Ethical committee of Lisbon and Oporto regions; the National Commission for Health Data Safety.

Romania Scientific Committee of CPSS.

Spain

Research Units of Primary Care of the Autonomous Community in the Basque Country. In all other Autonomous Communities, the study was approved at the Healthcare Area level.

Slovakia The national coordinator consulted the Council of the Slovak Society of General Practice. It was confirmed that there is no statutory requirement for ethical approval for this study.

Slovenia National medical ethics committee.

Sweden Regional Research Ethics Committte.

Switzerland Ethical Committee of the University of Lausanne.

Turkey Ethical committee of Kartal Research and Education Hospital in Istanbul.

United University of Lincoln School of Health and Social Care Ethics Kingdom Committee; National Research Ethics Service.

aSee: Wong ST, Chau LW, Hogg W et al. An international cross-sectional survey on the Quality and Costs of Primary Care (QUALICO-PC): recruitment and data collection of places delivering primary care across Canada. BMC Family Practice (2015) 16:20.

\section{Competing interests}

The authors declare that they have no competing interests.

\section{Publisher's Note}

Springer Nature remains neutral with regard to jurisdictional claims in published maps and institutional affiliations.

\section{Author details}

'Laboratorio Management e Sanità, Institute of Management, Scuola Superiore Sant'Anna, Pisa, Italy. ${ }^{2}$ Netherlands Institute for Health Services Research-NIVEL, Utrecht, The Netherlands. ${ }^{3}$ Department of General Practice, University Medical Center Göttingen, Göttingen, Germany. ${ }^{4}$ Department of Nursing and Health Sciences, University of Applied Sciences Fulda, Fulda, Germany. ${ }^{5}$ Department of Sociology, Department of Human Geography, Utrecht University, Utrecht, The Netherlands.

Received: 11 December 2016 Accepted: 6 February 2018

Published online: 21 February 2018

\section{References}

1. Afrite $A$, Bourgueil $Y$, Daniel F, Mousquèsa F, Couralet $P E$, Chevillard $G$. The impact of multi-professional group practices on healthcare supply. Evaluation aims and methods for "maisons", "pôles de santé" and "centres de santé" within the framework of experiments with new mechanisms of remuneration. Questions d'économie de la santé. 2013;189:1-6.

2. Atenstaedt R. Single-handed or group practice, quality of care and patient satisfaction. Br J Gen Pract. 2006;56(525):301. 
3. Baker $\mathrm{R}$, Streatfield J. What type of general practice do patients prefer? Exploration of practice characteristics influencing patient satisfaction. $\mathrm{Br} J$ Gen Pract. 1995 Dec;45(401):654-9.

4. Blount A. Integrated primary care: organizing the evidence. Families,Systems Health. 2003;21(2):121-3.

5. Bonciani M, Barsanti S, Matarrese D. Esperienze di integrazione nell'assistenza primaria basate sulla co-location dei servizi: quali prospettive per il modello della Casa della Salute? Mecosan. 2015;96:81-122.

6. Bonciani M, Barsanti S, Murante AM. Is the co-location of GPs in primary care centres associated with a higher patient satisfaction? Evidence from a population survey in Italy. BMC Health Serv Res. 2017;17:248.

7. Bourgueil $Y$, Marek A, Mousquès J. Three models of primary care organisation in Europe, Canada, Australia and new-Zealand. Questions d'économie de la santé. 2009;189:1-6.

8 Calnan M, Williams S. Challenges to professional autonomy in the United Kingdom? The perceptions of general practitioners. Int J Health Serv. 1995; 25(2):219-41.

9 Cameron A, Lart R, Bostock L, Coomber C. Factors that promote and hinder joint and integrated working between health and social care services: a review of research literature. Health Social Care Community. 2014;22(3):22533. https://doi.org/10.1111/hsc.12057.

10 Campbell SM, Hann M, Hacker J, et al. Identifying predictors of high quality care in English general practice: observational study. BMJ. 2001;323:784-7.

11 Coburn AF. Models for integrating and managing acute and long-term care services in rural areas. J Appl Gerontol. 2001;20:386-408.

12 Collins C, Hewson DL, Munger R, Wade T. Evolving models of behavioral health integration in primary care. New York: Milbank Memorial Fund; 2010.

13 Jong JDd. Explaining medical practice variation. Social organization and institutional mechanisms. Utrecht: Nivel; 2007

14 Donabedian A. The quality of care: how can it be assessed? JAMA. 1988; 260(12):1743-8.

15 Freeman T, Peck E. Evaluating partnerships: a case study of integrated specialist mental health services. Health Soc Care Community. 2006;14(5): 408-17. https://doi.org/10.1111/j.1365-2524.2006.00658.x.

16 Frost N, Robinson M, Anning A. Social workers in multidisciplinary teams: issues and dilemmas for professional practice. Child Family Social Work. 2005;10(3):187-96.

17 Frost N. Professionalism, partnership and joined-up thinking: a research review of front-line working with children and families. Dartington: Research in practice; 2005. ISBN 0-904984-04-5.

18 Gibb C, Morrow M, Clarke C, Cook G, Gertig P, Ramprogus V. Transdisciplinary working: evaluating the development of health and social care provision in mental health. J Ment Health. 2002;11(3):339-50.

19 Ginsburg S. Colocating health services: a way to improve coordination of children's health care? Commonwealth Fund pub. 2008;1153(41):1-12. PMID: 18642477

20 Goodwin N, Perry C, Dixon A, Ham C, Smith J, Davies A, Rosen R, Dixon J. Integrated Care for Patients and Populations: improving outcomes by working together. London: The King's Fund; 2012.

21 Groenewegen P, Greß S, Schäfer W. General Practitioners' Participation in a Large, Multicountry Combined General Practitioner-Patient Survey: Recruitment Procedures and Participation Rate. International Journal of Family Medicine. 2016:4929432;1-9.

22 Groenewegen PP, Heinemann S, Greß S, Schäfer W. Primary care practice composition in 34 countries. Health Policy. 2015;119:1576.

23 Grol R. Successes and failures in the implementation of evidence-based guidelines for clinical practice. Med Care. 2001;39((8) Suppl 2):46-54.

24 Ham C. Only connect. Policy options for integrating health and social care. London: The Nuffield Trust; 2009.

25 Hillege S, Coulon L, Swann W, Wilson K. Nurse practitioners' experiences of working collaboratively with general practitioners and allied health professionals in new South Wales, Australia. Aust J Adv Nurs. 2005;23(2):22-7.

26 Humphries R, Curry N. Integrating health and social care. Where next? London: The King's Fund; 2011

27 Imison C, Naylor C, Maybin J. Under one roof: will polyclinics deliver integrated care? London: The King's Fund; 2008

28 Jung HP, Wensing M, Olesen F, Grol R. Comparison of patients' and general practitioners' evaluations of general practice care. Qual Saf Health Care. 2002;11:315-9.

29 Katon W, Von Korffb M, Lin E, Simon G. Rethinking practitioner roles in chronic illness: the specialist, primary care physician, and the practice nurse. Gen Hosp Psychiatry. 2001;23(3):138-44.
30 Kringos D, Boerma W, Bourgueil Y, Cartier T, Dedeu T, Hasvold T, Hutchinson A, Lember M, Oleszczyk M, Rotar Pavlic D, Svab I, Tedeschi P. Wilm S, Wilson A, Windak A, Van der Zee J, Groenewegen P. The strength of primary care in Europe: an international comparative study. Br J Gen Pract. 2013 Nov;63(616):e742-50.

31 Kringos D, Boerma W, Hutchinson A, van der Zee J, Groenewegen P. The breadth of primary care: a systematic literature review of its core dimensions. BMC Health Serv Res. 2010;10:65.

32 Kringos D, Boerma W, Bourgueil Y, Cartier T, Hasvold T, Hutchin-son A, et al. The European primary care monitor: structure, processand outcome indicators. BMC Fam Pract. 2010;11:81.

33 Kringos D, Boerma W, Hutchinson A, Saltman R. Building primary care in a changing Europe. Observatory Studies Series n.38. Copenaghen: World Health Organisation; 2015.

34 Kvarnström S. Difficulties in collaboration: a critical incident study of interprofessional healthcare teamwork. J Interprof Care. 2008;22(2):191-203.

35 Laurant M, Reeves D, Hermens R, Braspenning J, Grol R, Sibbald B. Substitution of doctors by nurses in primary care. Cochrane Database Systematic Reviews. 2005;2:CD001271.

36 Lawn S, Lloyd A, King A, Sweet L, Gum L. Integration of primary health services: being put together does not mean they will work together. BMC Research Notes. 2014;7:66. https://doi.org/10.1186/1756-0500-7-66.

37 Legido-Quigley H, Panteli D, Car J, McKee M, Busse R. Clinical guidelines for chronic conditions in the European Union. Observatory Study Series n. 30 Copenaghen: World Health Organisation; 2013.

38 Lloyd J, Wait S. Integrated care: a guide for policymakers. London: Alliance for Health and the Future; 2005.

39 Maslin-Prothero Sian E., Amy E. Bennion. Integrated team working: a literature review. International Journal of Integrated Care. 2010;10:1-11.

40 Mitchell GK, Tieman JJ, Shelby-James TM. Multidisciplinary care planning and teamwork in primary care. MJA. 2008;188:S61-4.

41 Mitchell R, Parker V, Giles M, White N. Toward realizing the potential of diversity in composition of interprofessional health care teams: an examination of the cognitive and psychosocial dynamics of interprofessional collaboration. Med Care Res Rev. 2010;67(1):3-26.

42 Oandasan IF, Gotlib CL, Lingard L, Karim A, Jakubovicz D, Whitehead C, Mille K-L, Kennie N, Reeves S. The impact of space and time on Interprofessional teamwork in Canadian primary health care settings: implications for health care reform. Primary Health Care Res Dev. 2009;10(2):151-62.

43 Papp R, Borbas I, Dobos E, Bredehorst M, Jaruseviciene L, Vehko T, Balogh S. Perceptions of quality in primary health care: perspectives of patients and professionals based on focus group discussions. BMC Fam Pract. 2014;15:128.

44 Rotar-Pavlič D, Sever M, Klemenc-Keti Z, Svab I. Process quality indicators in family medicine: results of an international comparison. BMC Fam Pract. 2015;16:172.

45 Pecukonis E, Doyle O, Bliss DL. Reducing barriers to interprofessional training: promoting interprofessional cultural competence. J Interprof Care. 2008;22(4):417-28

46 Piterman L, Koritsas S, Part I. General practitioner-specialist relationship. Intern Med J. 2005;35:430-4.

47 Rosemann T, Wensing M, Joest K, Backenstrass M, Mahler C, Szecsenyi J. Problems and needs for improving primary care of osteoarthritis patients: the views of patients, general practitioners and practice nurses. BMC Musculoskelet Disord. 2006;7:48.

48 Rumball-Smith J, Wodchis WP, Koné A, Kenealy T, Barnsley J, Ashton T. Under the same roof: co-location of practitioners within primary care is associated with specialized chronic care management. BMC Fam Pract. 2014;15:149. https://doi.org/10.1186/1471-2296-15-149.

49 Rutter D, Tyrer P, Emmanuel J, Weaver T, Byford S, Hallam A, Simmonds S, Ferguson B. Internal vs. external care management in severe mental illness: randomized controlled trial and qualitative study. J Ment Health. 2004;13(5):453-66

50 Schäfer W, Boerma W, Murante M, Sixma H, Schellevis F, Groenewegen P. Assessing the potential for improvement of primary care in 34 countries: a cross-sectional survey. Bull World Health Organ. 2015;93:161-8.

51 Schäfer WL, Boerma WG, Kringos DS, De Maeseneer J, Gress S, Heinemann S, Rotar-Pavlic D, Seghieri C, Svab I, Van den Berg MJ, Vainieri M, Westert GP, Willems S, Groenewegen PP. QUALICOPC, a multi-country study evaluating quality, costs and equity in primary care. BMC Fam Pract. 2011;12:115.

52 Schäfer WL, Boerma WG, Kringos DS, De Ryck E, Greß S, Heinemann S, Murante AM, Rotar-Pavlic D, Schellevis FG, Seghieri C, Van den Berg MJ, Westert GP, Willems S, Groenewegen PP. Measures of quality, costs and 
equity in primary health care instruments developed to analyse and compare primary care in 35 countries. Qual Prim Care. 2013;21(2):67-79.

53 Schmied V, Mills A, Kruske S, Kemp L, Fowler C, Homer C. The nature and impact of collaboration and integrated service delivery for pregnant women, children and families. J Clin Nurs. 2010;19:3516-26.

54 Shaw S, Rosen R, Rumbold B. What is integrated care? London: The Nuffield Trust; 2011.

55 Smith Susan M, Soubhi H, Fortin M, Hudon C, O'Dowd T. Managing patients with multimorbidity: systematic review of interventions in primary care and community settings. BMJ. 2012;345:e5205.

56 Sommers LS, Marton Kl, Barbaccia JC, Randolph J. Physician, nurse, and social worker collaboration in primary Care for Chronically ill Seniors. Arch Intern Med. 2000;160(12):1825-33.

57 Suter E, Oelke ND, Adair CE, Armitage GD. Ten key principles for successful health systems integration. Healthcare Quarterly (Toronto, Ont). 2009;13:1623. PMCID: PMC3004930

58 van Bodegom-Vos L, de Jong SP, Curfs E, Groenewegen P. Are patients' preferences for shifting services from medical specialists to general practitioners related to the type of medical intervention? Qual Prim Care. 2013;21:81-95

59 Whitfield M, Bucks R. General practitioners' responsibilities to their patients. BMJ. 1988:297(6645):398-400.

\section{Submit your next manuscript to BioMed Central and we will help you at every step:}

- We accept pre-submission inquiries

- Our selector tool helps you to find the most relevant journal

- We provide round the clock customer support

- Convenient online submission

- Thorough peer review

- Inclusion in PubMed and all major indexing services

- Maximum visibility for your research

Submit your manuscript at www.biomedcentral.com/submit 